\title{
Spectral structure of mesoscale winds over the water
}

\author{
Larsén, Xiaoli Guo; Vincent, Claire Louise; Larsen, Søren Ejling
}

Published in:

Quarterly Journal of the Royal Meteorological Society

Link to article, DOI:

10.1002/qj.2003

Publication date:

2013

Document Version

Publisher's PDF, also known as Version of record

Link back to DTU Orbit

Citation (APA):

Larsén, X. G., Vincent, C. L., \& Larsen, S. E. (2013). Spectral structure of mesoscale winds over the water. Quarterly Journal of the Royal Meteorological Society, 139(672), 685-700. https://doi.org/10.1002/qj.2003

\section{General rights}

Copyright and moral rights for the publications made accessible in the public portal are retained by the authors and/or other copyright owners and it is a condition of accessing publications that users recognise and abide by the legal requirements associated with these rights.

- Users may download and print one copy of any publication from the public portal for the purpose of private study or research.

- You may not further distribute the material or use it for any profit-making activity or commercial gain

- You may freely distribute the URL identifying the publication in the public portal

If you believe that this document breaches copyright please contact us providing details, and we will remove access to the work immediately and investigate your claim 


\title{
RMetS
}

Royal Meteorological Society

\section{Spectral structure of mesoscale winds over the water}

\author{
Xiaoli Guo Larsén*, Claire Vincent and Søren Larsen \\ Risø National Laboratory for Sustainable Energy, Technical University of Denmark, Roskilde, Denmark \\ ${ }^{\star}$ Correspondence to: X. G. Larsén, Technical University of Denmark, Postbox 49, 4000 Roskilde, Denmark. \\ E-mail: xgal@dtu.dk
}

Standard meteorological measurements from a number of masts around two Danish offshore wind farms have been used to study the spectral structure of the mesoscale winds, including the power spectrum, the co- and quadrature spectrum and the coherence. When average conditions are considered, the power spectra show universal characteristics, in agreement with the findings in literature, including the energy amplitude and the $-5 / 3$ spectral slope in the mesoscale range transitioning to a slope of -3 for synoptic and planetary scales. The integral time-scale of the local weather is found to be useful to describe the spectral slope transition as well as the limit for application of the Taylor hypothesis. The stability parameter calculated from point measurements, the bulk Richardson number, is found insufficient to represent the various atmospheric structures that have their own spectral behaviours under different stability conditions, such as open cells and gravity waves. For stationary conditions, the mesoscale turbulence is found to bear some characteristics of two-dimensional isotropy, including (1) very minor vertical variation of spectra; (2) similar spectral behaviour for the along- and across-wind components; and (3) the along- and across-wind components at one point are not correlated. Copyright (C) 2012 Royal Meteorological Society

Key Words: $\quad$ power spectrum; cospectrum; quadrature spectrum; coherence; Taylor hypothesis

Received 18 January 2012; Revised 30 May 2012; Accepted 21 June 2012; Published online in Wiley Online Library

Citation: Larsén XG, Vincent C, Larsen S. 2012. Spectral structure of mesoscale winds over the water. Q. J. R. Meteorol. Soc. DOI:10.1002/qj.2003

\section{Introduction}

The spectral behaviour of the wind speed in the mesoscale range, from a few kilometres to hundreds of kilometres, or from a few minutes to hours, is not only a fundamental atmospheric research topic (e.g. Gage and Nastrom, 1986; Lindborg, 1999; Lindborg et al., 2010; Högström et al., 1999), but also important for practical use in wind energy applications. Modern wind farms are of the size of tens of kilometres, which means that the power spectrum in the mesoscale range is an important measure of accuracy for short-term forecasting (Vincent et al., 2010) as well as extreme wind estimation (Larsén et al., 2012). The spatial coherence of wind is a key parameter for wind energy planning and power integration (Sørensen et al., 2002; Vincent et al., 2012) for a single farm as well as for groups of farms within a limited geographical area such as the North
Sea. It is the purpose of this study to examine the spectral behaviour (including the power spectrum and coherence) in this range.

\subsection{The power spectrum}

In the literature, spatial mesoscale power spectra have been studied with measurements from aircraft (e.g. Nastrom and Gage, 1985; Högström et al., 1999) and satellite (e.g. Wikle et al., 1999), with theoretical arguments (Lindborg, 1999) and with numerical simulations (Tung and Orlando, 2002; Skamarock, 2004). The scope of these studies ranges from the atmospheric surface layer to the troposphere and lower stratosphere, and from tropical to midlatitude and polar regions. Compared to the microscale range, the observed wind spectra in the mesoscale range seem to be rather simple: negligible dependence on height within the boundary 
layer (Högström et al., 1999; Larsén et al., 2011), and only slightly higher energy amplitude in the stratosphere than in the troposphere according to upper-air measurements (Nastrom and Gage, 1985; Gage and Nastrom, 1986). Kao and Wendell (1970) and Nastrom and Gage (1985) observed the dependence of the energy amplitude on latitude from data measured with commercial aircraft; the tropospheric energy amplitude for the meridional winds seemed to be largest in the latitude band $45-60^{\circ} \mathrm{N}$. Nastrom and Gage (1985) also observed that the energy amplitude is smallest in summer and Boer and Shepherd (1983) observed that, for planetary and synoptic scales, the energy amplitude is greatest in winter.

In spite of these variabilities, one consistent characteristic of the spectrum reported in the literature is the spectral form that the energy amplitude decreases with wave number as approximately $k^{-5 / 3}$ in the mesoscale range and changes to $k^{-3}$ at smaller wave numbers. An expression, in terms of a combination of $k^{-3}$ and $k^{-5 / 3}$, which Lindborg (1999) derived through structure function analysis for the kinetic energy spectrum in the meso- to synoptic scales fits perfectly the experimental data from Nastrom and Gage (1985) and Gage and Nastrom (1986):

$$
E\left(k_{1}\right)=d_{1} k_{1}^{-5 / 3}+d_{2} k_{1}^{-3}
$$

with $d_{1} \approx 9.1 \times 10^{-4} \mathrm{~m}^{4 / 3} \mathrm{~s}^{-2}$ and $d_{2} \approx 3.0 \times 10^{-10} \mathrm{~s}^{-2}$. We use $k_{1}$ for Lindborg's expression because it is in $\mathrm{m}^{-1}$, different from the other studies where the wave number is in radian $\mathrm{m}^{-1}$ (used in section 5.3).

The generally accepted theoretical interpretation of the $k^{-3}$ behaviour is the enstrophy (mean square vorticity) cascade from large scale to small scale, and that of the $k^{-5 / 3}$ behaviour is the energy cascade from small scale to large scale. As illustrated in Gage and Nastrom (1986) (their Figure 1), the source for enstrophy injection at the largescale end of the $k^{-3}$ region of the spectrum is the geostrophic turbulence that is related to the baroclinic instability, and the source of the energy injection at the small-scale end of $k^{-5 / 3}$ could be the buoyancy force such as gravity waves (Gage and Nastrom, 1986) or convective cloud systems (Lilly, 1983). This theory for quasi-two-dimensional (2D) turbulence was first presented by Kraichman (1967) and Batchelor (1969), supported over time by numerous theoretical, numerical and experimental studies, including Lilly and Petersen (1983), Gage and Nastrom (1986), Lindborg (1999), Shivamoggi (2000), Tung and Orlando (2002) and Lindborg et al. (2010). Experiments also suggested that the mesoscale 2D flow has some isotropy characteristics, reflected as the lateral and meridional wind components having very similar spectral form (Gage and Nastrom, 1986; Högström et al., 1999; Larsén et al., 2011). However, the isotropy was reported to be invalid in the presence of coherent gravity waves where more kinetic energy was found to be distributed along the wave-propagating direction (Larsén et al., 2011).

\subsection{The coherence}

Compared to the power spectra, coherence for the mesoscale range has been much less explored. Vincent et al. (2012) (hereafter V2012) summarized the limited number of studies of coherence in the mesoscale range, including Schlez and Infield (1998), Sørensen et al. (2002), Nanahara et al. (2004), and Woods et al. (2011). These studies are almost all for wind energy applications. In the literature, coherence is mainly studied in the microscale range, from metres to hundreds of metres, or from seconds to minutes (Davenport, 1961; Kristensen et al., 1983; Smedman, 1987; Mann, 1994). V2012 studied the coherence of wind speed in terms of the two components of coherence, the co- and quadrature spectra, for offshore conditions in the Baltic Sea and the North Sea, where mesoscale modelling, analytical modelling and measurements were used jointly for separation distances between a couple of kilometres and about $13 \mathrm{~km}$. Amongst other things, V2012 found that

(1) the two-point coherence depends on the flow angle in relation to the line connecting the points in question;

(2) the coherence can be expressed as a function of frequency $(f)$, separation distance $(d)$ and advection speed $\left(U_{0}\right): f d / U_{0}$; and

(3) the coherence has slight dependence on the studied area where the dominant weather features might be different.

\subsection{Relevance and focus of the current study}

In most of the studies in the literature, the spectra were analyzed in the spatial domain in terms of wave number, $k$. The corresponding measurements from aircraft and satellites have a wide spatial coverage but with segments of relatively short periods. Point measurements have been paid less attention for this purpose, even though they are much easier to access, partly because of the difficulties associated with Doppler shifting associated with gravity waves (section 5.3 gives details).

Considering that the time- and space-scales are related, point measurements are expected to provide information for planetary to micro-scales which are relevant for the energy amplitude in the mesoscale range. Longterm standard meteorological measurements from two midlatitude offshore sites with several tall masts are used to re-examine the spectral behaviour regarding the spectral form and amplitude as well as coherence of wind speed. This dataset provides us with a unique opportunity for looking into some of the classic topics on the spectral characteristics. Three particular topics are studied: (i) the spectral shape and amplitude, (ii) the impact of stability on the mesoscale spectral structure from the most explored stable condition to the rarely mentioned neutral and unstable conditions; and (iii) the 2D isotropy characteristics of the mesoscale turbulence.

The use of the long-term point measurements is directly relevant to wind energy applications. The analysis covers a wide frequency range, allowing an examination of the impact of annual, seasonal and diurnal variability. It will be shown that the spectral behaviour suggests a relevant scale for our study of spatial coherence.

The measurements are introduced in section 2 together with the climatological background at the two sites. The methods for calculating and presenting the power spectra and the coherence are given in section 3 . The results of power spectra and coherence are presented in sections 4.1 and 4.2 respectively. Discussion and conclusions follow in sections 5 and 6 . 
(a)

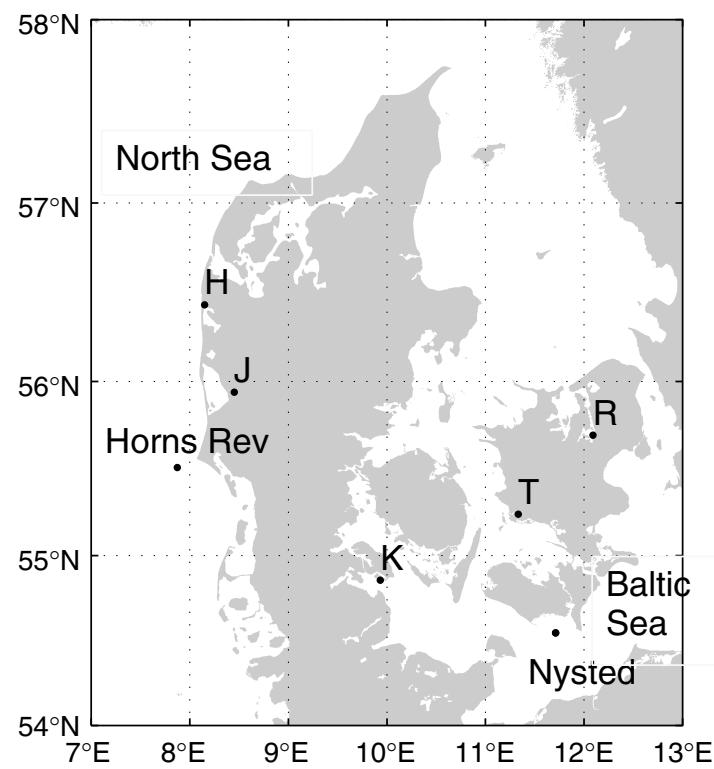

(b)

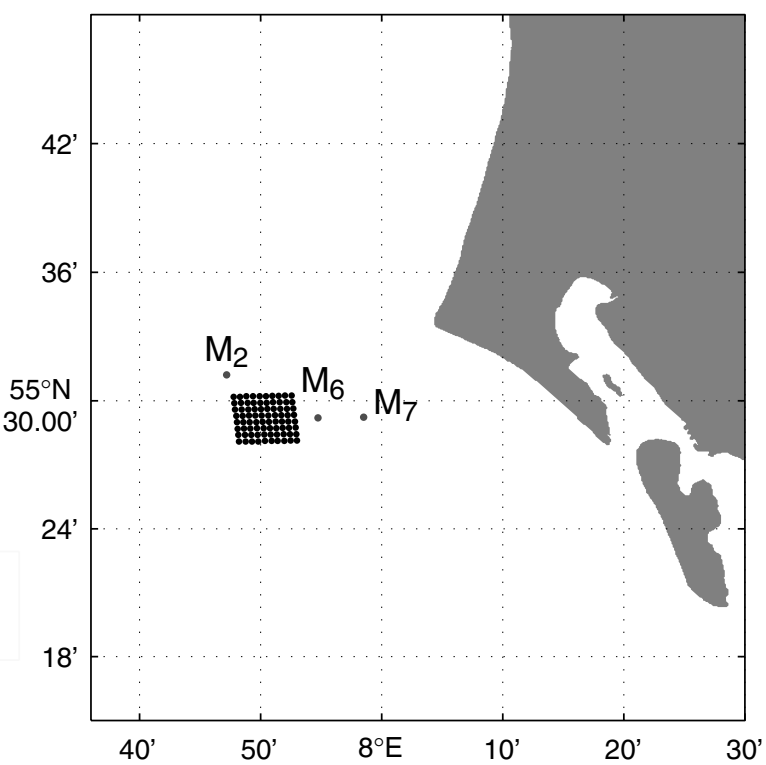

(c)

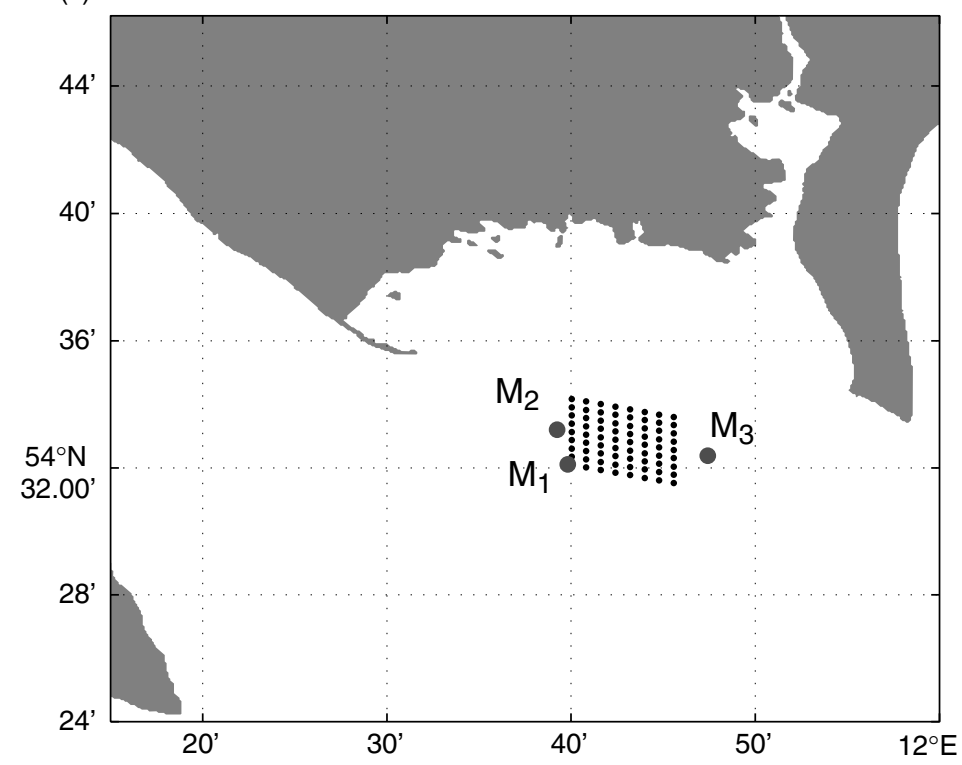

Figure 1. Maps and sites. (a) Map of Denmark and locations of Nysted, Horns Rev and several other stations labelled as H (Høvsøre), J (Jylex), K (Kegnæs), T (Tystofte), R (Risø). (b) The three masts and the wind farm at Horns Rev. (c) The three masts and the wind farm at Nysted.

\section{Measurements and climatology at Nysted and Horns} $\operatorname{Rev}$

The meteorological measurements are from masts around two wind farms in Denmark. Horns Rev I is located offshore in the North Sea (Figure 1(a,b)), and Nysted is located offshore in the semi-enclosed water which is part of the Baltic Sea (Figure 1(a,c)).

At the Nysted wind farm there are several meteorological masts, three of which are used in this study (Figure 1(c)), where the wind speeds were measured with cup anemometers at heights above mean sea level of 10, 25, 40, 55, 65 and $69 \mathrm{~m}$. Wind vanes and temperature sensors were mounted at 10 and $65 \mathrm{~m}$. Air pressure was measured at $10 \mathrm{~m}$. From pressure and temperature, the potential temperature was calculated. Water temperature was available at $2 \mathrm{~m}$ depth at masts $2\left(M_{2}\right)$ and $3\left(M_{3}\right)$.
Around the Horns Rev wind farm, there are three masts (Figure $1(\mathrm{~b}))$. Only mast $2\left(M_{2}\right)$ existed before the wind farm was built in 2003. On $M_{2}$, wind speeds were measured at $15,30,45$ and $62 \mathrm{~m}$ (mast top), wind directions at 60 and $43 \mathrm{~m}$, temperatures at 55 and $13 \mathrm{~m}$ and pressure at $55 \mathrm{~m}$. Water temperature has been measured at $4 \mathrm{~m}$ depth. Since 2003 , masts $6\left(M_{6}\right)$ and $7\left(M_{7}\right)$ have been mounted with instrumentation different from $M_{2}$; the wind measurements were measured at 20,30, 40, 50, 60 and $70 \mathrm{~m}$ (mast top), directions at 28 and $68 \mathrm{~m}$, temperature at 16 and $64 \mathrm{~m}$ and pressure at $16 \mathrm{~m}$. Wind measurements at some heights are missing during some periods, especially those at 30 and $40 \mathrm{~m}$.

For both sites, the time series used for the main analysis here are $10 \mathrm{~min}$ averages. The wind data availability for each mast at the two sites is shown in Table 1. For a special analysis of a gravity wave case (section 5.4), $1 \mathrm{~s}$ time series at Nysted are also used. 
Table 1. Yearly wind data coverage (\%) at each mast at the two sites.

\begin{tabular}{lccclll}
\hline Year & \multicolumn{3}{c}{ Nysted } & & \multicolumn{2}{c}{ Horns Rev } \\
\cline { 2 - 3 } \cline { 5 - 6 } & $M_{1}$ & $M_{2}$ & $M_{3}$ & & $M_{2}$ & $M_{7}$ \\
\hline 1999 & & & & 60 & \\
2000 & & & & 99.975 & \\
2001 & & & & 99.979 & \\
2002 & & & & 99.9 & 46 \\
2003 & & & & 99.79 & 90 \\
2004 & 52 & 52 & 52 & & 86 & 98 \\
2005 & 95 & 95 & 95 & & 73 \\
2006 & 92 & 92 & 92 & & \\
2007 & 52 & 52 & 53 & & 20 & 73 \\
2008 & 35 & 41 & 41 & &
\end{tabular}

Although both sites are offshore and geographically close to each other, the climatology is different regarding the stability conditions and wind distribution due partly to the different configuration of land and water around the sites. The Nysted wind farm, located in semi-enclosed waters off the Baltic Sea and surrounded by land with relatively short sea fetches, has been reported to be dominated by climatologically stable conditions due predominantly to advection from land (Lange et al., 2004; Larsén et al., 2011). At Horns Rev, the prevailing westerly winds from the open North Sea often accompany convective weather systems (Vincent et al., 2012a). The monthly distributions of the Richardson numbers at the two sites are presented in Figure 2, clearly confirming the climatologically stable conditions at Nysted and unstable conditions at Horns Rev.

The bulk Richardson numbers are calculated by two methods. The first method is as in Larsén et al. (2011), i.e. use of measurements at two heights to calculate

$$
R i_{\mathrm{B}}=\frac{g}{\bar{\theta}} \frac{\Delta \theta}{\Delta z} /\left(\frac{\Delta U}{\Delta z}\right)^{2} .
$$

The two levels are 10 and $62 \mathrm{~m}$ at Nysted, and 15 and $45 \mathrm{~m}$ at Horns Rev; the temperatures at 15 and $45 \mathrm{~m}$ for the
Horns Rev data are linearly interpolated from temperature measurements at 16 and $64 \mathrm{~m}$. The other method is to calculate the bulk Richardson number between water surface and the lowest wind measurement level through

$$
R_{\mathrm{B}}=\frac{g}{\bar{T}} \frac{\left(T-T_{\mathrm{w}}\right)}{z} /\left(\frac{U}{z}\right)^{2} .
$$

Due to the fact that the temperature gradient between two levels on $M_{6}$ and $M_{7}$ at Horns Rev are sometimes problematic and give suspicious statistics, and at the same time that there have been concerns about the water temperature measurements at Nysted, both $R i_{\mathrm{B}}$ and $R_{\mathrm{B}}$ are calculated whenever data are available at a certain mast, so that they can be used as reference for each other. Note that, for the Nysted site, in Figure $2(\mathrm{a}, \mathrm{c}), R i_{\mathrm{B}}$ and $R_{\mathrm{B}}$ were calculated with the combined data at $M_{2}$ and $M_{3}$ from their undisturbed fetches because of the availability of water temperature measurements at the two masts. The results of $R i_{\mathrm{B}}$ were found to be consistent with those from $M_{1}$, even with the disturbed fetches included. For the Horns Rev site, in Figure 2(b), the calculation of $R i_{\mathrm{B}}$ is done at $M_{2}$ for the period 1999 to 2005 and in Figure 2(d), $R_{\mathrm{B}}$ has been calculated at $M_{7}$ for the period 2003 to 2007.

When producing the monthly statistics, the monthly data are used only if the data coverage is more than $90 \%$ at Nysted, and more than 99\% at Horns Rev; this is because the data coverage is significantly better at the latter site (Table 1). Note that the calculation of $R_{\mathrm{B}}$ is rather uncertain by using water temperature ( $4 \mathrm{~m}$ deep at Horns Rev and $2 \mathrm{~m}$ deep at Nysted) and temperature, rather than potential temperature, evem though Peña et al. (2008) showed that, at $M_{2}$ at Horns Rev, the water temperature matched well with the sea surface temperature obtained from satellite data. This, together with the different levels used for calculating $R i_{\mathrm{B}}$ and $R_{\mathrm{B}}$, is actually of minor significance since our purpose is not to parametrize the stability effects but to use $R i_{\mathrm{B}}$ and $R_{\mathrm{B}}$ to group data into different approximate stability (a)

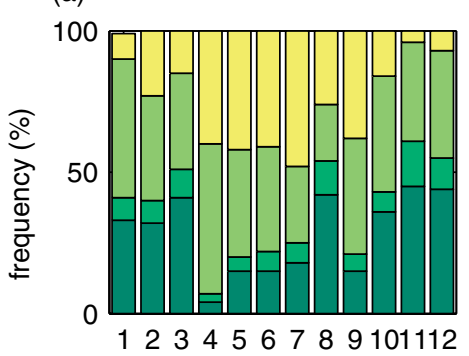

(c)

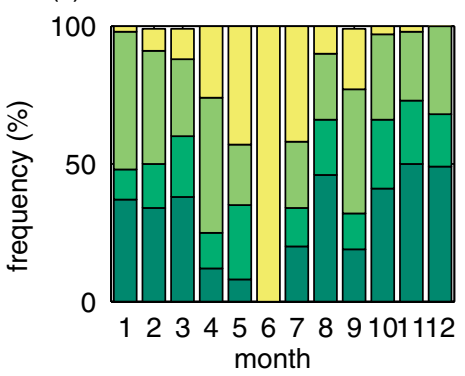

(b)

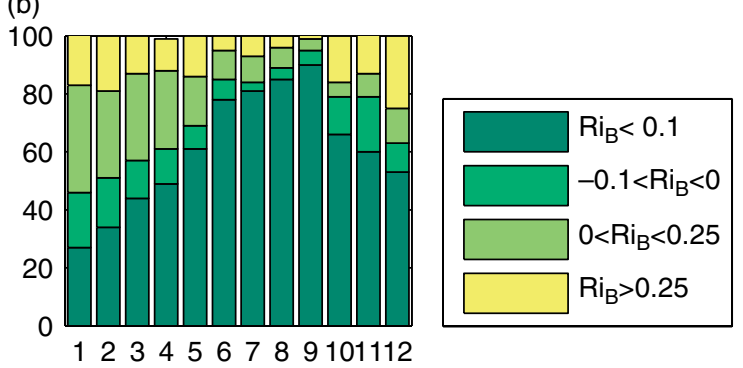

(d)

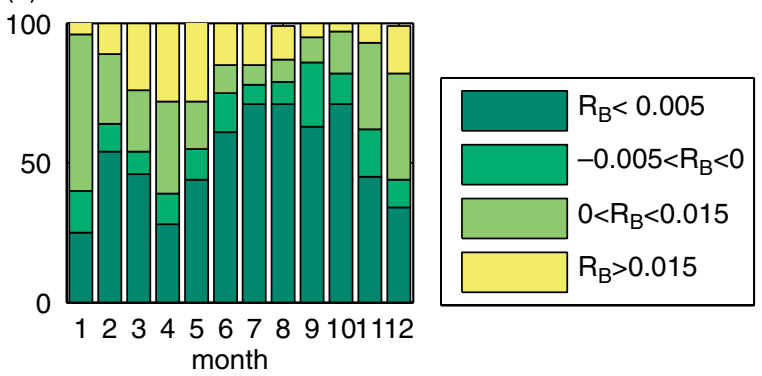

Figure 2. Monthly distribution of the bulk Richardson number at (a,c) Nysted and (b, d) Horns Rev. In (a) and (b), the bulk Richardson number $R i_{\mathrm{B}}$ is calculated between two measuring heights, i.e. 10 to $60 \mathrm{~m}$ at Nysted and 15 to $45 \mathrm{~m}$ at Horns Rev. In (c) and (d), the bulk Richardson number $R_{\mathrm{B}}$ is calculated between water surface and the lowest wind measurement height. This figure is available in colour online at wileyonlinelibrary.com/journal/qj 
categories. We see from Figure 2 that in general the statistics of $R i_{\mathrm{B}}$ and $R_{\mathrm{B}}$ are consistent, although the relative percentage could vary somewhat when choosing different critical values for the grouping. Even though the data are not always from the same periods and not necessarily from the same masts, the consistent statistics from $R i_{\mathrm{B}}$ and $R_{\mathrm{B}}$ strongly suggest the reliability of each of them for our grouping purposes and also suggest their representativity for the description of the stability climate.

At Nysted, the stable situation is more related to flows from the sector east-south-northwest while the sector north-northeast contributes more to the unstable conditions. At Horns Rev, the unstable conditions are related to flow from the sea while stable conditions are more related to the flow from land.

In any climatological study, data length, data coverage, technical failure and operating consistency always present a challenge. Even so, the datasets here, being in pairs at multiple levels up to about $70 \mathrm{~m}$, and of reasonably good quality, are quite unique. Basic data quality checks have been done and problematic data are not used in the final results. The over-speeding effect of the Risø cup anemometers used at both sites is only a fraction of $1 \%$ for average atmospheric conditions (Pedersen et al., 2003; Pedersen, 2004).

\section{Methods}

\subsection{The power spectrum}

The power spectra have been calculated using the Fourier transform, with linear detrending applied to the time series.

In order to examine the climatological characteristics, the annual and seasonal variability in the spectra is investigated (section 4.1.1). The annual spectra are calculated only for those years with best data coverage, where the missing data are filled in using linear interpolation with data before and after the gaps. As shown in Table 1, the Nysted data are used from 2005 and 2006 and the Horns Rev data are used from 2000 to 2002 at $M_{2}$ and 2005 at $M_{7}$. For the seasonal spectra, only months with data coverage greater than $95 \%$ are used for Nysted (due to the relatively low data coverage) and 99.9\% for Horns Rev. From the Horns Rev data, it is found that changing the requirement of data coverage from $99 \%$ to $90 \%$ does not change the results, suggesting that using data of $95 \%$ coverage at Nysted does not cause statistically significant bias.

With the purpose of examining the stability effect and the $2 \mathrm{D}$ characteristics of the mesoscale turbulence, we examined scales smaller than one day, by analyzing daily spectra (section 4.1.2). All days that have 143 (the one missing data is linearly interpolated to give $14410 \mathrm{~min}$ values) or $14410 \mathrm{~min}$ data values are selected. For all these days, it is required that the wind speed at the top measuring height does not vary more than $15 \mathrm{~m} \mathrm{~s}^{-1}$ per day and the direction change during a day is less than $50^{\circ}$. This ensures that the cases chosen for analysis approximate stationary conditions in order to be able to divide the wind into the along-wind $(u)$ and cross-wind $(v)$ components. Data within these restrictions are nominated as 'stationary data'. For the Horns Rev site, this analysis is done both for the period 1999 to 2002 and for the period 1999 to 2007. The former period predated the wind farm and measurements at $M_{2}$ from all directions were used; for the latter period, at $M_{2}$ only data free of the wind farm wakes were selected. Using the time series 1999 to 2007 and grouping the data into three $R_{\mathrm{B}}$ categories $\left(R_{\mathrm{B}}>0.05,0 \leq R_{\mathrm{B}} \leq 0.05\right.$ and $\left.R_{\mathrm{B}}<0\right)$ gives almost the same spectral statistics as using the time series 1999 to 2002 and $R i_{\mathrm{B}}$. The consistency of the results suggests the period was reasonably representative.

\subsection{The coherence}

The coherence was calculated from a block-averaged single realization of the spectra and cross-spectra, as in V2012. This method was shown by Kristensen and Kirkegaard (1986) to be equivalent to averaging over a large number of time series. (V2012 gives a detailed discussion.) The time series went through linear detrending and a Hanning window was applied before the coherence parameters were calculated.

The coherence study here was carried out to examine the $u$ and $v$ component behaviour in comparison with the wind speed, the vertical variation coherence and the effect of local stability (section 4.2). These issues were not the major subjects in V2012 where spatial correlations of wind speeds were studied. Because of our different focus, we construct and select the data slightly differently from V2012. The basic data length is still one day. As for the calculation of the daily $u$ and $v$ power spectra, we select the stationary data. While V2012 extensively explored the effect of the inflow angle relative to the mast pair's orientation, we focus on two specific situations: the inflow along (longitudinal separation) and across (lateral separation) the displacement of the two masts. All data are required to be free of the wind farm wake effect. The direction restriction for the two situations for each pair of masts is described in Table 2. At Nysted, three pairs of the three masts are used for the lateral separation study, but the cases are too few for the longitudinal separation situation. At Horns Rev, only the pair with longest separation, $M_{2}$ and $M_{7}$, is used. Because of the requirement of 144 or $14310 \mathrm{~min}$ per day for a pair of masts simultaneously, the number of days satisfying each category is much smaller than for the power spectra analysis (Table 2). When $R_{\mathrm{B}}$ is used to group the data, $R_{\mathrm{B}}>0.015,0 \leq R_{\mathrm{B}} \leq 0.015$ and $R_{\mathrm{B}}<0$ are used, representing stable, neutral to stable (shortened to neutral) and unstable conditions, respectively. A sensitivity test is done by changing the critical threshold of $R_{\mathrm{B}}$ from 0.015 to 0.05 ; the largest consequence was that there were too few cases in the stable category. However, the statistical results are consistent. $R_{\mathrm{B}}$ is used only for Horns Rev because of the unknown problems in the temperature gradient at $M_{7}$. For Nysted, $R i_{\mathrm{B}}$ is used in order to make use of more data, and the corresponding three stability categories according to the daily mean $R i_{\mathrm{B}}$ are $R i_{\mathrm{B}}>0.1,0 \leq R i_{\mathrm{B}} \leq 0.1$ and $R i_{\mathrm{B}}<0$. Similarly, using a threshold value of 0.1 to group the data will gives similar statistics, but using (e.g.) 0.25 will result in too few cases in the first group.

The coherence between the time series at two locations, $i$ and $j$, is calculated using

$$
\operatorname{Coh}(f)=\sqrt{\operatorname{Co}_{n}(f)^{2}+Q_{n}(f)^{2}},
$$

where $\mathrm{Co}_{n}$ and $Q_{n}$ are normalized co- and quadrature spectrum (Co and $Q)$ :

$$
C o_{n}(f)=\frac{C o(f)}{\sqrt{S_{i}(f) S_{j}(f)}}, \quad Q_{n}(f)=\frac{Q(f)}{\sqrt{S_{i}(f) S_{j}(f)}} .
$$

As discussed in V2012, $C o_{n}$ and $Q_{n}$ together represent the in-phase and out-of-phase contribution to covariance of the 
Table 2. Pairs of masts and data description for the co- and quadrature spectrum and coherence studies, including the masts' orientation, separation distance and the number of cases (in days) that satisfy the direction range used for selecting data for lateral or longitudinal separation conditions.

\begin{tabular}{|c|c|c|c|c|c|c|}
\hline Site & Masts & Orientation & Distance (m) & Direction range & & Number \\
\hline \multirow[t]{3}{*}{ Nysted } & $M_{1}, M_{2}$ & $165^{\circ}$ & 2130 & $231-290^{\circ}$ & $(\perp)$ & 75 \\
\hline & $M_{1}, M_{3}$ & $82^{\circ}$ & 8178 & $136-200^{\circ}$ & $(\perp)$ & 36 \\
\hline & $M_{2}, M_{3}$ & $100^{\circ}$ & 8903 & $177-217^{\circ}$ and $0-25^{\circ}$ & $(\perp)$ & 32 \\
\hline \multirow[t]{3}{*}{ Horns Rev } & $M_{2}, M_{7}$ & $109^{\circ}$ & 12420 & $94-118^{\circ}$, from land & $(\|)$ & 33 \\
\hline & & & & $270-304^{\circ}$, from sea & $(\|)$ & 150 \\
\hline & & & & $180-215^{\circ}$ and $0-30^{\circ}$ & $(\perp)$ & 101 \\
\hline
\end{tabular}

$\|$ denotes longitudional separation and $\perp$ lateral separation.

(a)

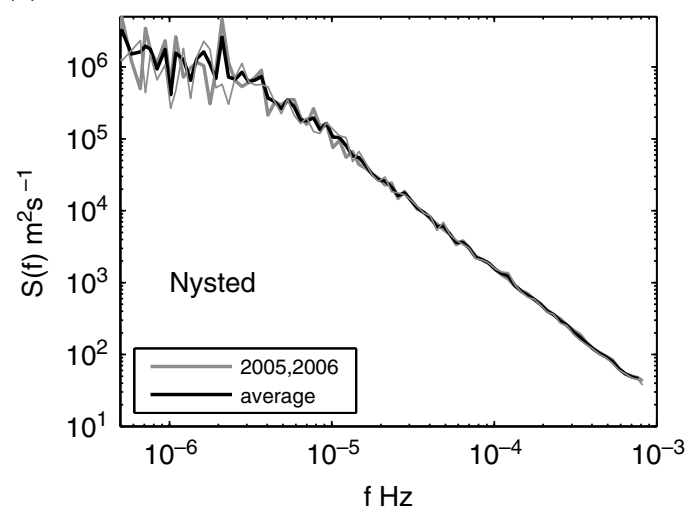

(c)

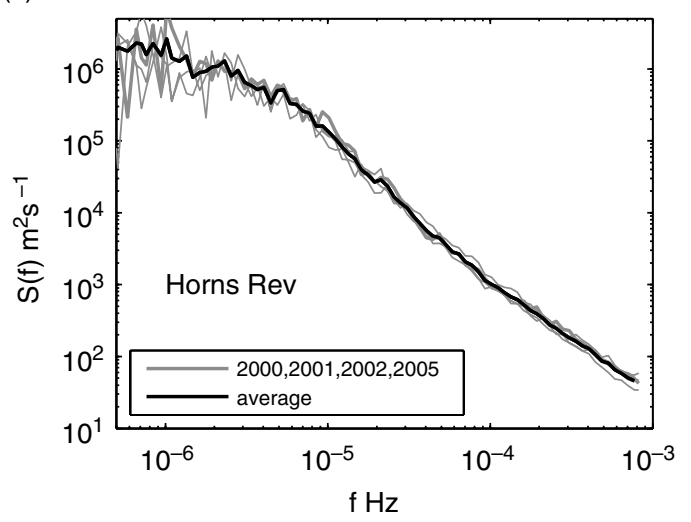

(b)

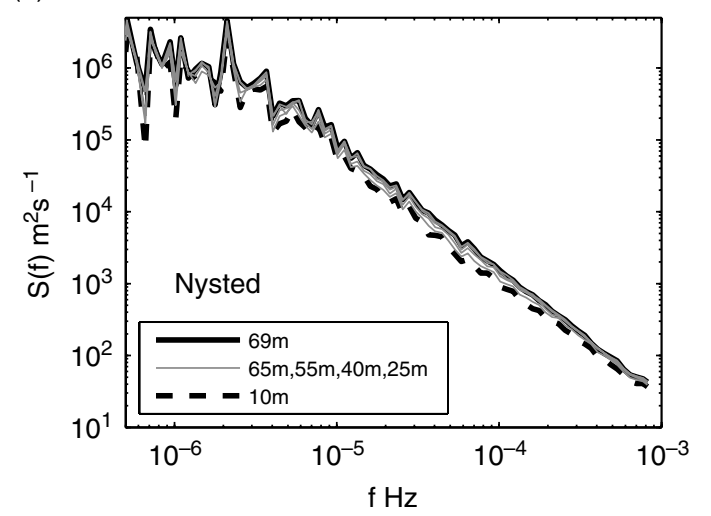

(d)

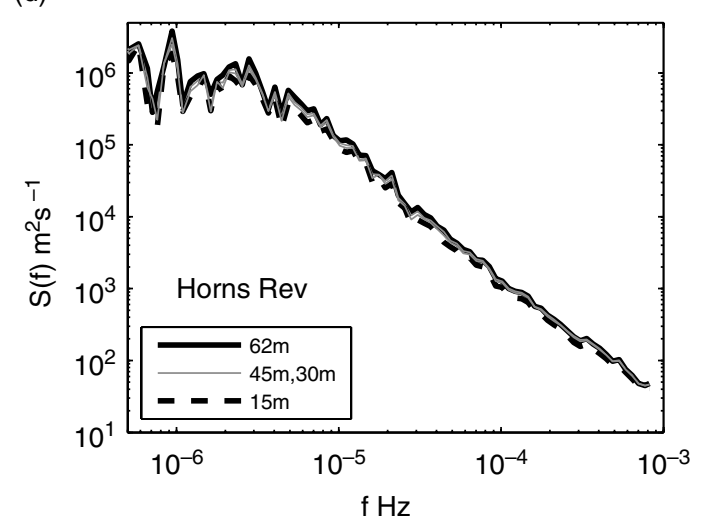

Figure 3. Power spectra from 1-year time series at (a,b) Nysted $M_{1} 69 \mathrm{~m}$ and (c, d) Horns Rev $M_{2} 62 \mathrm{~m}$. (a, c) show spectra from different years and an average spectrum for the site; $(b, d)$ show spectra at several heights.

two time series at points $i$ and $j . S_{i}$ and $S_{j}$ are the power spectra at $i$ and $j$ respectively. In the current study, the power spectral energy in the frequency domain is denoted as $S(f)$, to be distinguished from $E(k)$ for the wave number domain. Coh, $\mathrm{Co}_{n}$ and $Q_{n}$ have been calculated for the wind speed and its two components, $u$ and $v$, at all measuring heights.

\section{Results}

\subsection{The power spectrum}

\subsubsection{Annual and seasonal spectra}

There is almost no difference in the annual spectra from different masts for the same year. The year to year variation in the spectrum is obviously not important, as can be seen from Figures 3(a) (Nysted) and 3(c) (Horns Rev). The results in Figure 3 from data over several years demonstrate the following systematic differences: the logarithmic slope of the spectra in the range $5 \times 10^{-6}<f<10^{-3} \mathrm{~Hz}$ is straighter at Nysted than that at Horns Rev, where the spectra show a much clearer slope transition at a frequency of around $10^{-4.5} \mathrm{~Hz}$. In Figure $3(\mathrm{~b}, \mathrm{~d})$, the spectra at several measurement heights are plotted, indicating that there is some degree of vertical variation, which is more obvious at Nysted than at Horns Rev; the ratio of $S(f)$ is about 1.5 between 55 and $10 \mathrm{~m}$ at Nysted and about 1.3 between 62 and $15 \mathrm{~m}$ at Horns Rev throughout the whole frequency range. Comparing Figures 3(c) and (d), one can see that at Horns Rev the height dependence is systematic but is not more significant than the annual variability.

The average annual power spectra from the two sites are put together in Figure 4 and the difference in the energy amplitude is actually very small, with the ratio of $S(f)$ on average 1.01 for $5 \times 10^{-6}<f<10^{-3} \mathrm{~Hz}$, even though the Horns Rev spectrum shows stronger curvature. 


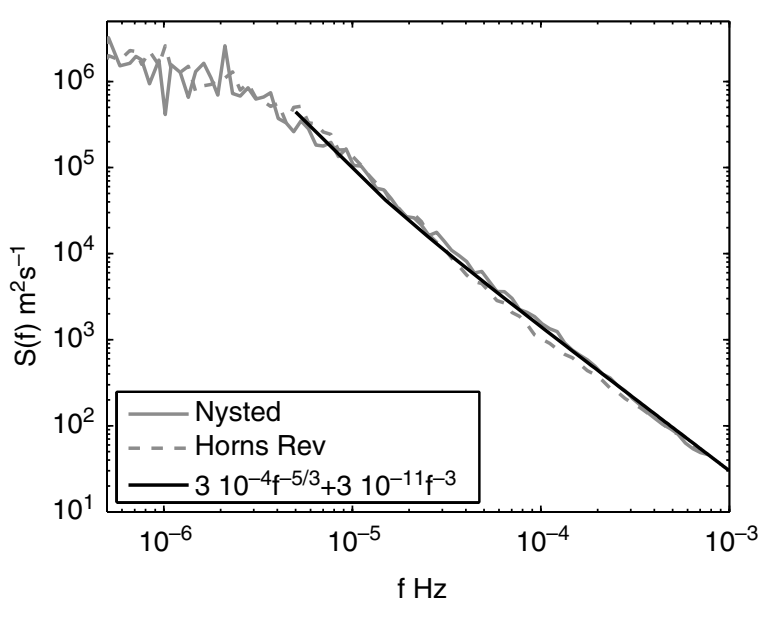

Figure 4. The yearly average power spectra from Nysted and Horns Rev, taken from solid black curves in Figure 3(a,c) together with the model of Eq. (4).

In analogy to Lindborg's model, Eq. (1), the black curve in Figure 4 shows the fit combining $f^{-5 / 3}$ and $f^{-3}$; this gives a very satisfactory agreement with

$$
S(f)=a_{1} f^{-5 / 3}+a_{2} f^{-3},
$$

where $a_{1}=3 \times 10^{-4} \mathrm{~m}^{2} \mathrm{~s}^{-8 / 3}$ and $a_{2}=3 \times 10^{-11} \mathrm{~m}^{2} \mathrm{~s}^{-4}$.

The seasonal power spectra from the two sites are shown in Figure 5(a, b). It is immediately clear that summer months exhibit a straighter spectrum where $S(f)$ varying with $f^{-5 / 3}$ extends to a very low frequency, whereas the winter months exhibit a higher energy amplitude and a clearer slope transition from $-5 / 3$ to -3 at a relatively high frequency of about $2 \times 10^{-5} \mathrm{~Hz}$ (about half a day); Figures 5(c, d) show the winter and summer cases, respectively. Spring and autumn will inevitably share the characteristics somewhere between winter and summer. The stronger geostrophic turbulence effect reflected in the -3 slope denotes a coefficient $a_{2}$ for winter being several times larger than for summer. Data from the two sites are highly consistent, in agreement with the findings in the $k$ domain in Nastrom and Gage (1985) and Boer and Shepherd (1983) (section 5.3); the stronger baroclinic instability in winter months is a reasonable interpretation. The overall annual spectrum from Horns Rev resembles the winter spectrum more than at Nysted, which could imply that the open sea condition at Horns Rev better reflects the geostrophic turbulence than Nysted where the mesoscale land impact could be significant.

\subsubsection{Power spectra in the mesoscale range}

For the range with the $-5 / 3$ spectral slope, based on Figures 3 to 5 , it seems that when all conditions are mixed and averaged, the energy amplitude for both sites reaches a certain level; the dependence on year, height and season can all be considered small. In the following we examine this range by analyzing the daily spectra, to determine the possible impact of stability and to explore the $2 \mathrm{D}$ spectral quality. In Figure 6, the mean values of the daily spectra for three stability categories are plotted for Nysted and Horns Rev, together with their average annual spectra from Figure 3(a,c). For Horns Rev, data from 1999 to 2002 are used (42, 18 and 197 in the three stability categories). For Nysted, due to the strict restrictions for the stationary conditions, there are only 36, 42 and 86 days in the three categories.

For the neutral group, the mean spectra of both $u$ and $v$ are very close to the average annual spectra. For the stable group at Nysted, the mean spectrum exhibits considerably lower energy amplitude than the average annual curve. However, at Horns Rev the mean spectrum for stable cases is quite close to the average annual curve. For the unstable group at Horns Rev, the mean spectrum is of considerably larger energy amplitude at the high frequencies than the average annual curve (Figure 6(g)), but this effect is not at all obvious for the Nysted data (Figure 6(c)). Figure 6(g) was based on almost 200 days of data; it is quite clear that the dominating unstable conditions at Horns Rev are responsible for the enhanced energy amplitude in the high-frequency part of the mesoscale range, particularly in the winter and autumn seasons, as seen in Figure 5(b). These results of higher energy amplitude during unstable conditions are consistent with the findings in Vincent et al. (2010) where a different spectrum analysis, using the Hilbert-Huang transform, was performed for this site.

For all groups in Figure 6, the spectra of $u$ and $v$ are highly similar. The ratio of the $u$ - and $v$-power spectrum, $S_{u}(f) / S_{v}(f)$, has been calculated and is presented in Figure $7(\mathrm{a})$. The values of $S_{u}(f) / S_{v}(f)$ fluctuate around 1 for $f<\sim 10^{-4} \mathrm{~Hz}$ and about 1.2-1.3 for higher $f$. The ratio of $S_{u}(f) / S_{v}(f)$ for this range has earlier been examined in Larsen et al. (1990) using $16 \mathrm{~Hz}$ sonic data from the Lammefjord experiment. From data over 11 periods ranging from 8 to 20 h, Larsen et al. (1990) found similar spectral behaviour for $u$ and $v$ for $10^{-4}<f<10^{-3} \mathrm{~Hz}$, and $S_{u}(f) / S_{v}(f)$ to be about 1.5. It has been argued (e.g. Frehlich and Chelton, 1986) that physically for $2 \mathrm{D}$ isotropic turbulence, the $1 \mathrm{D}$ power spectrum of the component speed relative to the direction along which the spectrum is calculated (here $u$ ) will be greater than the $1 \mathrm{D}$ spectrum of the perpendicular component speed (here $v$ ). These characteristics were confirmed by Frehlich and Chelton (1986) with the Seasat scatterometer data in midlatitudes, but not satisfied by data from the Tropics. To further examine the assumption of non-divergent flow, Frehlich and Chelton (1986) studied the the 1D crossspectrum of two perpendicular wind components and found that they are not coherent, as would be expected for non-divergent flow. In this study, we also calculated the single-point coherence, co- and quadrature spectrum of $u$ and $v$ for three stability categories. The algorithms are similar to Eq. (2) and (3) for two points, except that here it is single point but for $u$ and $v$. Consistent with midlatitude data in Frehlich and Chelton (1986), we also observed negligible correlation between $u$ and $v$. The cospectra of $u$ and $v$ fluctuate around zero over the whole frequency range, even though the fluctuation could be rather large when the sample number is small, shown as $\operatorname{Co}_{n}(u, v)$ in Figure 7(b). At the same time, both the variations of Coh and $Q_{n}(u, v)$ with frequency are similar; they are all very close to zero over all frequencies (not shown).

\subsection{The coherence}

The mathematical descriptions of $\mathrm{Co}_{n}$ and $Q_{n}$ were given for the wind speed by Sørensen et al. (2002) and reformulated in V2012 as their Eqs (16)-(19). Combining these equations 
(a)

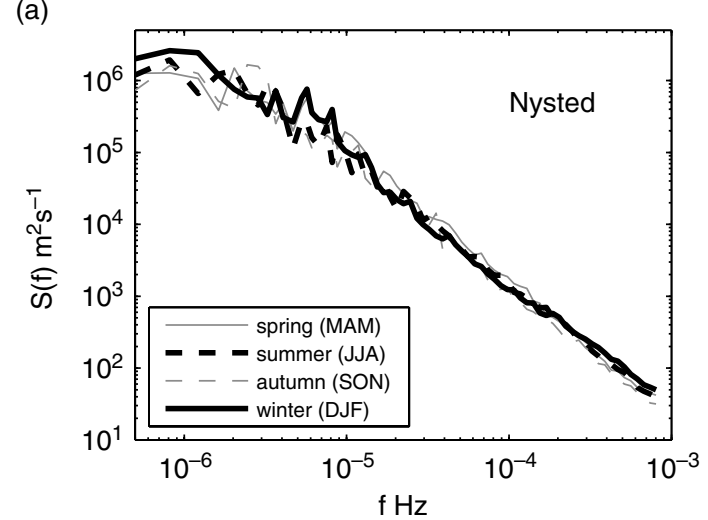

(c)

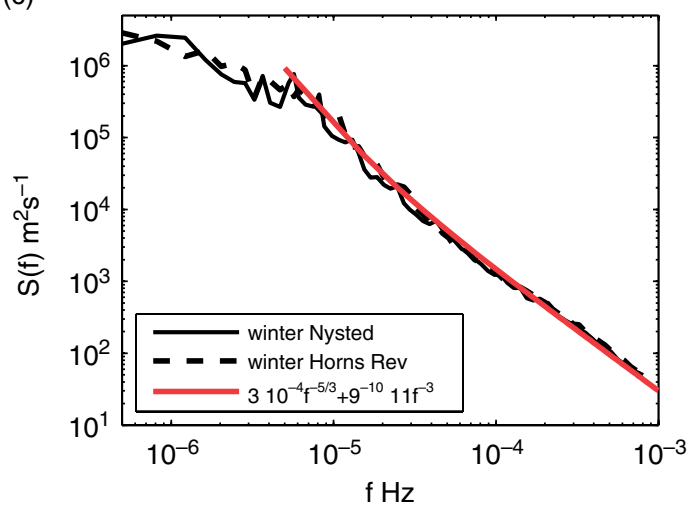

(b)

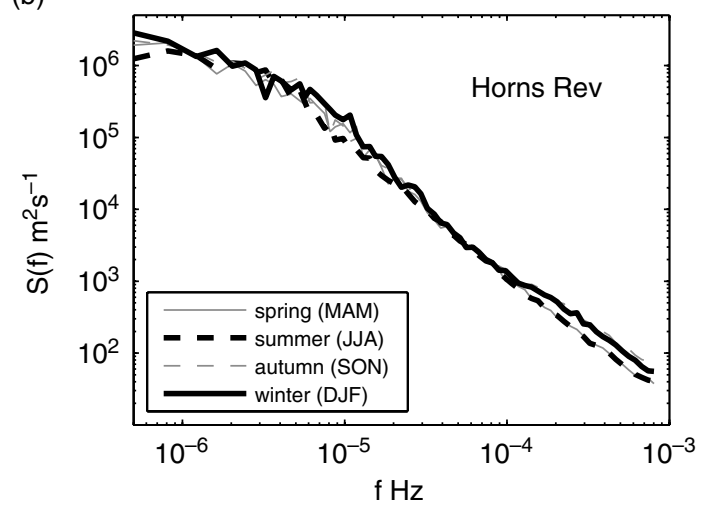

(d)

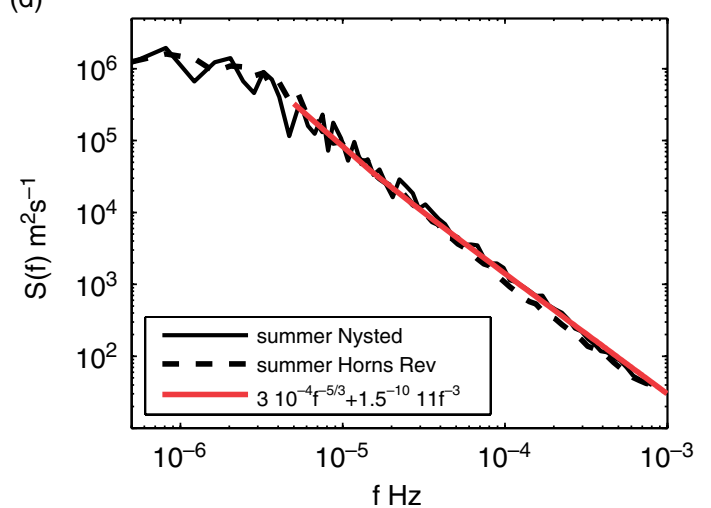

Figure 5. Power spectra in the four seasons at (a) Nysted and (b) Horns Rev. (c) shows winter months for Nysted and Horns Rev and from Eq. (4) with $a_{2}=9 \times 10^{-11}$. (d) shows summer months and from Eq. (4) with $a_{2}=1.5 \times 10^{-11}$. This figure is available in colour online at wileyonlinelibrary.com/journal/qj

gives

$$
\text { Coh }=\exp \left[\{1.8 \cos (2 \alpha)-5.9\} \frac{f d}{U_{0}}\right],
$$

where $\alpha$ is the flow angle relative to the mast orientation (here 90 and $270^{\circ}$ for the lateral separation and 0 and $180^{\circ}$ for the longitudinal separation), $d$ is the distance between a pair of masts, $U_{0}$ is the daily mean wind speed at corresponding heights (which for Nysted is $69 \mathrm{~m}$ and for Horns Rev is $62 \mathrm{~m}$; data from $M_{7}$ are interpolated to this height). Thus, $C o h=\exp \left(-7.7 f d / U_{0}\right)$ for the lateral separation, and Coh $=\exp \left(-4.1 f d / U_{0}\right)$ and Coh $=\exp \left(-5.9 f d / U_{0}\right)$ for the longitudinal separation with $\alpha=0$ and $180^{\circ}$, respectively. The longitudinal separation corresponds to better coherence at the same $f d / U_{0}$. The normalized frequency, $f d / U_{0}$, is equivalent to $k d /(2 \pi)$, with $k$ the radian wave number; it describes the number of waves within the separation distance $d$ of the pair of masts.

Only days with stationary wind conditions are analyzed. Although here the days are not necessarily the same as those selected in V2012 (discussion in section 3), the distribution of $C o_{n}$ and $Q_{n}$ for $u$ and $v$ here are consistent with those from V2012 for the wind speed in several respects. Figure 8 shows the three spectral variables for lateral separation for the top measuring height. Here, $\mathrm{Co}_{n}$ from two sites with different separation distances collapse to the same distribution, for both $u$ and $v ; Q_{n}$ fluctuates moderately around zero through all frequencies, indicating no systematic phase change at locations $i$ and $j$; Eq. (5) describes reasonably well the result for Coh, for both $u$ and $v$, as shown in Figure 8(c, f) despite the fact that in V2012 it was calculated for the scalar wind speed rather than $u$ and $v$ components. However, the plots for $v$ (Figure $8(\mathrm{~d}, \mathrm{e})$ ) reveal a couple of small but interesting differences. It seems that when the $u$ components are almost entirely uncorrelated for $f d / U_{0}>0.5$ (Figure $8(\mathrm{a})$ ), the $v$ components at the two masts, now aligning with the masts displacement, are negatively correlated with each other, shown as a dip to negative $C o_{n}$ in Figure $8(\mathrm{~d})$, in a similar fashion to $u$ and $v$ for the longitudinal separation situation (Figure 9) but to a much smaller degree. At the same time, $Q_{n}$ shows $v$ to be slightly but systematically out of phase at the two masts, most dominantly at $f d / U_{0} \approx 1 / 4$ (Figure $8(\mathrm{e})$ ).

Compared to the lateral separation, the longitudinal separation indicates a much more pronounced $Q_{n}$, both for $u$ and $v$ (Figure 9). Similar to the findings in V2012, here for $u$ and $v$, the flow from the undisturbed sea fetch also has better defined phase shift than the flow from land (not shown). When the winds come along the two masts, $C o_{n}$ for $u$ and $v$ decreases with $f d / U_{0}$, becomes negative at $f d / U_{0} \approx 0.25$ and reaches a maximum negative value at $f d / U_{0} \approx 0.5$, meaning $u$ or $v$ becomes negatively correlated at the two points once there is one quarter of the entire wave between $M_{2}$ and $M_{7}$, and they become most negatively correlated when there is half of the entire wave between the two masts. The correlation returns to be positive again when the wave number is greater than 1 . These characteristics of $u$ and $v$ are identical to those of wind speed as described in V2012 (curves from V2012 in Figure 9(c)).

There is no variation observed for the three parameters with height. The slight increase of the power spectral energy with height, as shown in Figure 3, is of negligible influence 
(a)

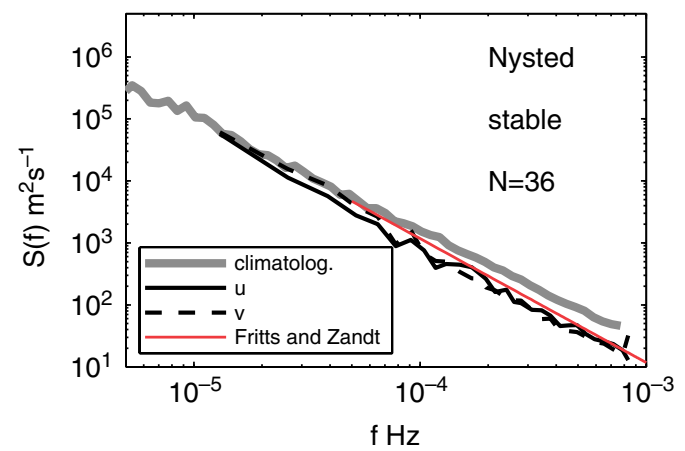

(b)

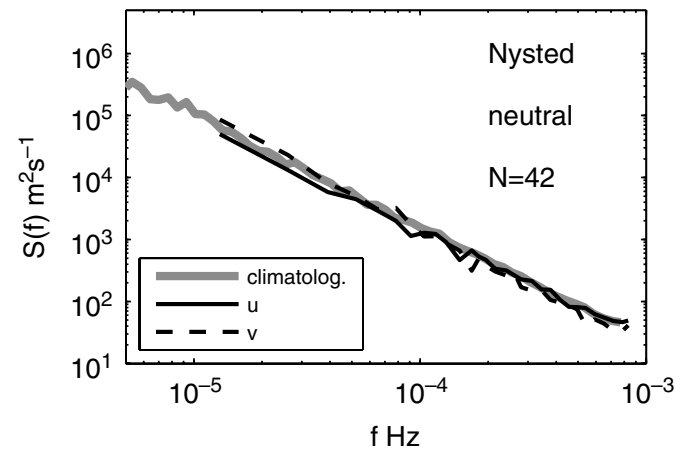

(c)

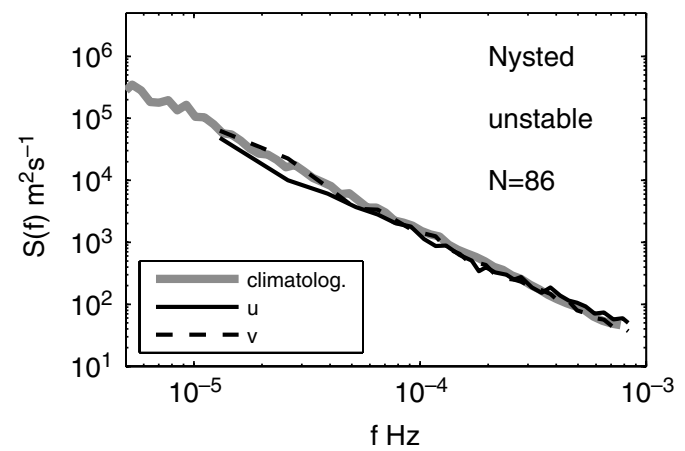

(d)

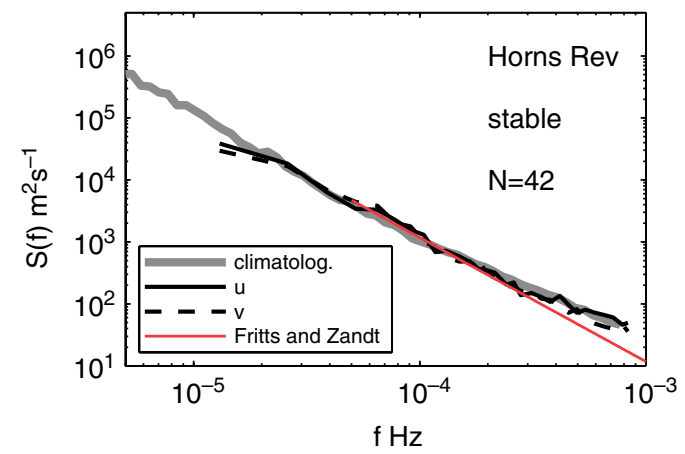

(e)

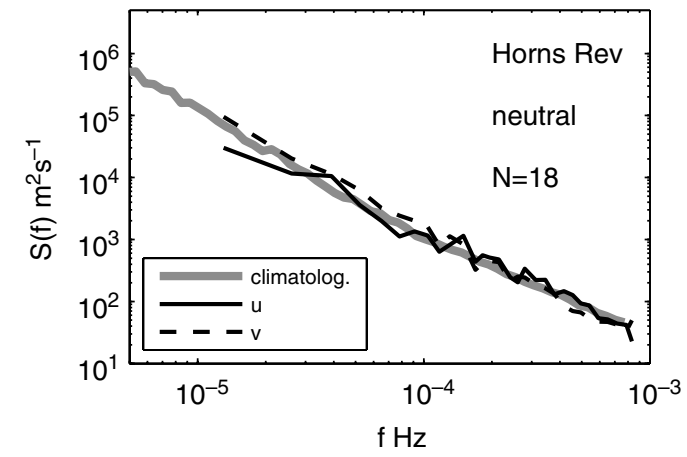

(f)

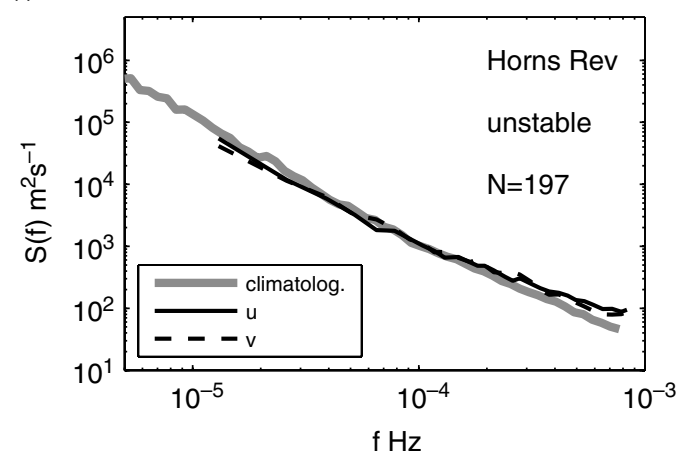

Figure 6. Power spectra from daily time series in three stability categories, with the daily mean (a,d) $R i_{\mathrm{B}}>0.1,(\mathrm{~b}, \mathrm{e}) 0 \leq R i_{\mathrm{B}} \leq 0.1$, and $(\mathrm{c}, \mathrm{f}) R i_{\mathrm{B}}<0$, for $(\mathrm{a}, \mathrm{b}, \mathrm{c})$ Nysted and $(\mathrm{d}, \mathrm{e}, \mathrm{f})$ Horns Rev. In $(\mathrm{a}, \mathrm{d})$ the thin straight line is $(1 / 2) S_{F}(f)$ given by Eq. (7) of Fritts and van Zandt (1987). This figure is available in colour online at wileyonlinelibrary.com/journal/qj

(a)

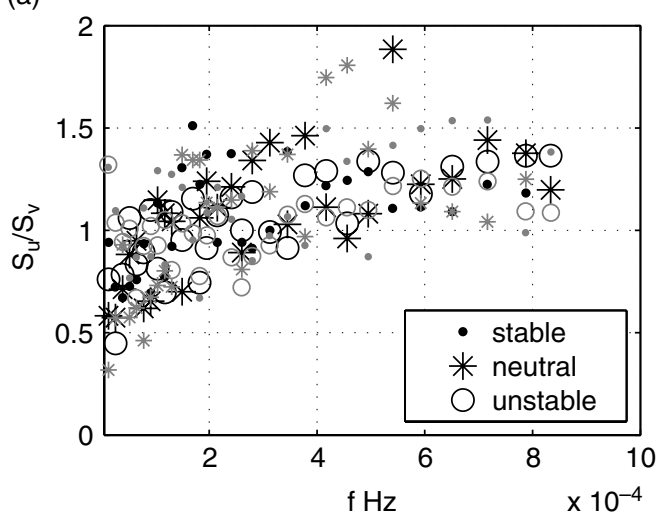

(b)

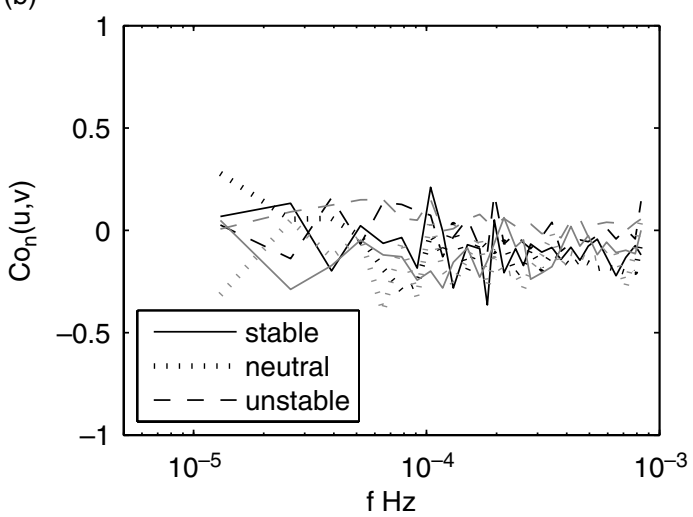

Figure 7. (a) The ratio of power spectra of $u$ to $v$ as a function of frequency $f$. (b) The one-dimensional normalized co-spectrum of $u$ and $v$. Data are from both Nysted (black) and Horns Rev (grey). 
(a)

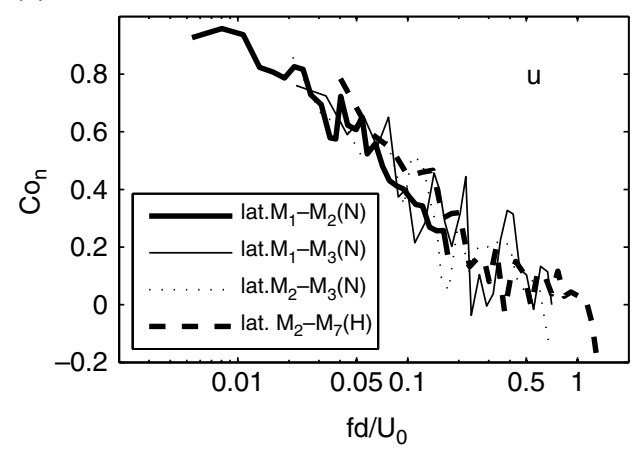

(b)

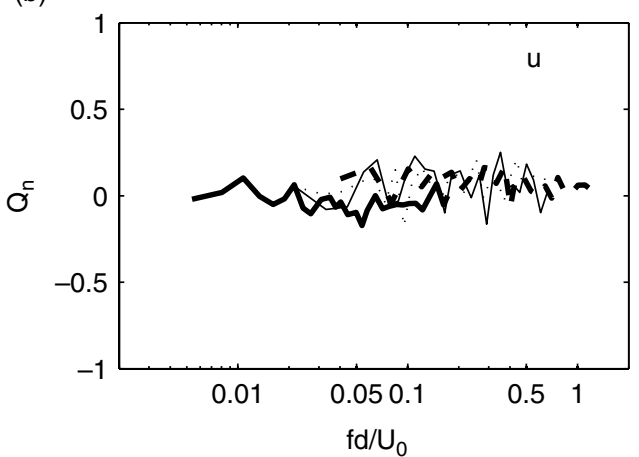

(c)

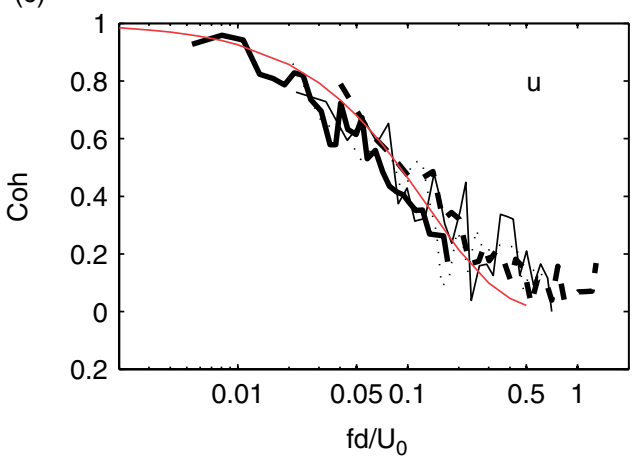

(d)

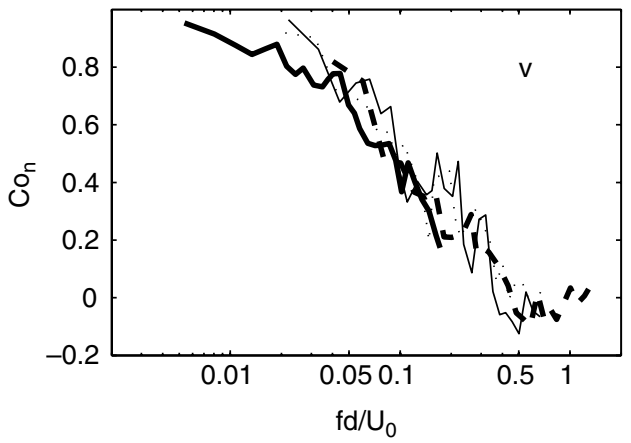

(e)

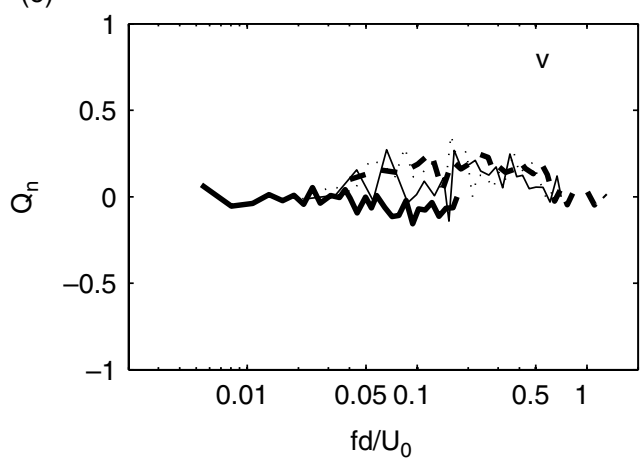

(f)

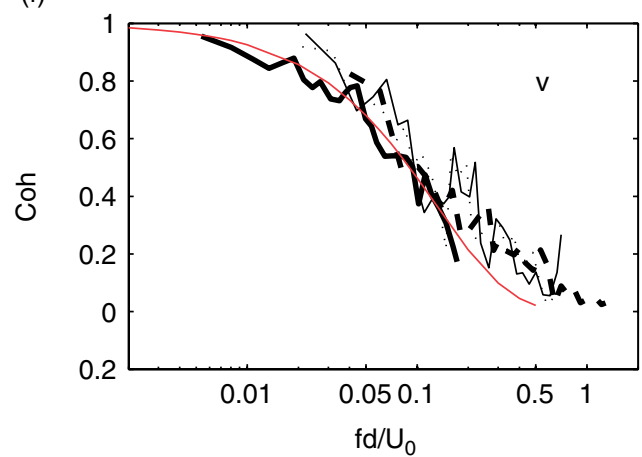

Figure 8. Lateral separation situations: $C o_{n}, Q_{n}$ and $C o h$ as functions of $f d / U_{0}$, for (a,b, c) $u$ and (d, e, f) $v$, for the three pairs of masts from Nysted (N in legend in (a)) and one pair from Horns Rev (H in legend in (a)). The smooth curves in (c) and (f) are the same: reference Eq. (5) derived with equations in V2012 with $\alpha=90^{\circ}$ or $270^{\circ}$. This figure is available in colour online at wileyonlinelibrary.com/journal/qj

when used in Eq. (3), probably due to the much more considerable scatter related to the coherence parameters.

The results from Horns Rev and Nysted seem to be highly consistent; there are respectively 143 and 284 days of data at Nysted and Horns Rev (Table 2).

In the analysis of stability effect, because of the high similarity in the distribution of Coh between the different groups as shown in Figures 8 and 9, we present only results of wind speed for two of the groups of lateral separation, one is $M_{1}-M_{2}$ at Nysted (Figure 10(a)) and the other is $M_{2}-M_{7}$ at Horns Rev (Figure 10(b)). When Coh is plotted against $f$, there is no distinguishable difference between the three groups of data, suggesting that stability impact is not important, although small differences could be obscured by the scatter in the data. However, there is a slight change when $C o h$ is plotted against $f d / U_{0}$ (not shown); due to the strongest winds in the neutral condition group and weakest winds in the stable condition group, there is a slight shift of the curves. As a result, at the same wave number $f d / U_{0}$, stable cases on average are best correlated and neutral cases are least correlated; however, the difference is very small compared to the scatter. For each stability group, in addition to the wind speed, Coh has also been calculated for the $u$ and $v$ components (not shown). Overall, Coh for $u, v$ and wind speed are very similar.

\section{Discussion}

We have shown the potential of the standard meteorological measurements from two offshore sites in midlatitudes for studying the spectral structures in the meso- to synoptic scales. Due to the continuity of scales in time and space, it has been demonstrated that point measurements can be used successfully to describe some spectral behaviours consistent with those in the literature, which have mostly been reported in the wave number domain.

There are several new findings within this study, giving rise to the following discussion topics.

\subsection{On the scale for applying the Taylor hypothesis}

We have chosen 1 day in this study for the length of the time series for the coherence analysis. This is partly because it has been reported in the literature that the Taylor hypothesis 

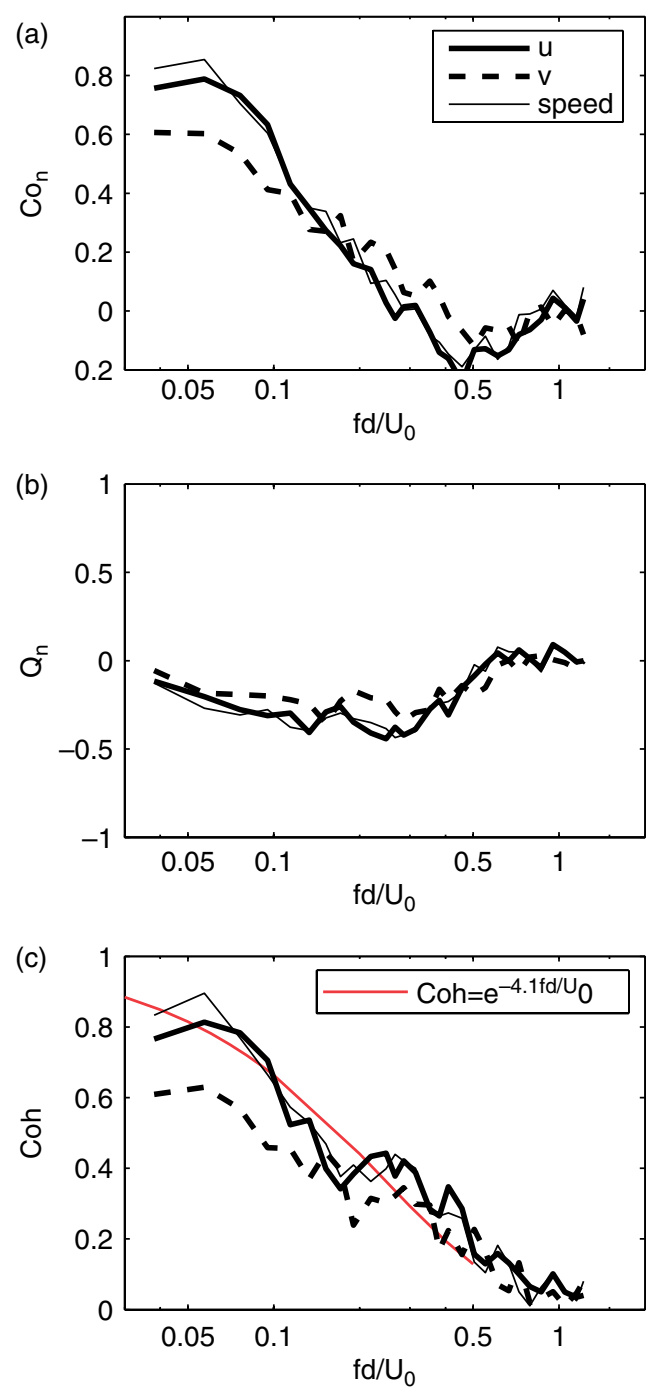

Figure 9. Longitudinal separation situations: (a) $\mathrm{Co}_{n}$, (b) $Q_{n}$ and (c) Coh as functions of $f d / U_{0}$, for $u, v$ and wind speed, for $M_{2}$ and $M_{7}$ at Horns Rev, with winds from the sea $\left(\alpha=0^{\circ}\right)$. In (c) the smooth curve is from Eq. (5) with $\alpha=0^{\circ}$. This figure is available in colour online at wileyonlinelibrary.com/journal/qj

has been successfully applied for scales of hundreds of kilometres, corresponding to periods shorter than about one day (Brown and Robinson, 1979; Gage and Nastrom, 1986).

Speaking of scales greater than a few kilometres or a few minutes, the documented structures in the literature include the power spectrum showing a slope of about $-5 / 3$ for relatively small scales and changing to a slope approaching -3 at larger scales, when plotted against frequency or wave number on log-log axes. Accompanying the observed most dominant -3 slope during winter months, there is a clearer slope transition than in the other months, especially the summer. In the summer months, the $-5 / 3$ spectral slope extends to a scale of days, while in the winter months the transition of the $-5 / 3$ to the -3 slope appears to happen at a smaller scale. This scale, where the spectral slope transition happens, represents the scale of the dominant local weather. The conventional parameter to describe this weather scale is the integral time-scale $T$, with

$$
T=\int_{0}^{\infty} \rho(\tau) \mathrm{d} \tau,
$$

where $\rho$ is the autocorrelation coefficient (Pope, 2000; Kristensen et al., 2002; Larsén et al., 2012). As shown in Larsén and Mann (2006) and Larsén et al. (2012), T calculated with measurements from Denmark is about 0.8 day on average. We calculated $T$ here using the winter and summer months data with data coverage of more than 99.99\%. While the summer months give a similar $T$ to the yearly data, i.e. about 0.8 day, winter months give a $T$ of about 0.6 day.

In turbulence theory, the spectra in the $k$ and $f$ domains are equivalent when space and time are assumed to be related by the advection velocity through the Taylor hypothesis

$$
\mathbf{k}=\frac{2 \pi f}{\mathbf{u}_{0}}
$$

Note that here $\mathbf{u}_{0}$ is used for the advection velocity, to represent an average, uniform background speed throughout a rather deep layer of atmosphere, rather than wind speed at one particular height such as $U_{0}$ the speed at the hub height, which we used for studying the coherence. However, $f / U_{0}$ is a similar scaling to $f / \mathbf{u}_{0}$. The expression $f d / U_{0}$ thus describes the number of waves at the hub height between the two points separated by a distance $d$. One would not expect it to make sense to use $f d / U_{0}$ to normalize the frequency axes of the co- and quadrature spectra if $U_{0}$ does not only represent the advection of the same flow between the two locations, but also includes impact from the geostrophic movement. If plotted versus $f$ only, the wind and its components are better correlated (at the same $f$ ) at shorter separation distances. If eddies in the one-day time series of all scales can be transported from one location to another through advection, we would expect the coherence to be 1 over all frequencies or wave numbers. The decreasing of coherence with increasing number of waves between the two locations suggests that the advection transports only the largest structures from one place to another, leading to the high coherence at the smallest wave number while the small-scale fluctuations stay less (or un)correlated.

The fact that $\mathrm{Co}_{n}$ and $\mathrm{Coh}$ as functions of $f d / U_{0}$ from both sites collapse onto a single curve suggests the validity of the Taylor hypothesis for the largest eddies. That is, the dominant atmospheric movement included in the selected daily time series is through advection. This seems to confirm that our choice of 1 day is reasonable as the basic data length for the coherence study.

The spectral analysis here suggests that $T$ is a useful scale to separate the synoptic and mesoscale ranges and it provides us a physical reason for choosing 1 day as the length for studying the spectral structure for the mesoscale range, although the difference in $T$ for the prevailing weather dynamics in winter and summer implies that some uncertainty has been introduced.

In section 5.3, it will be shown how the $k$-spectrum of Lindborg (1999) fits well with our $f$-spectrum through the Taylor transformation within the scale constraint of $T$.

\subsection{On the stability effect}

According to Figure 6, grouping the days into three stability categories reveals little systematic dependence of the wind spectra on the stability. Data from both sites tend to collapse with the climatological spectrum except for two situations: the stable group at Nysted and the unstable group at Horns Rev. 

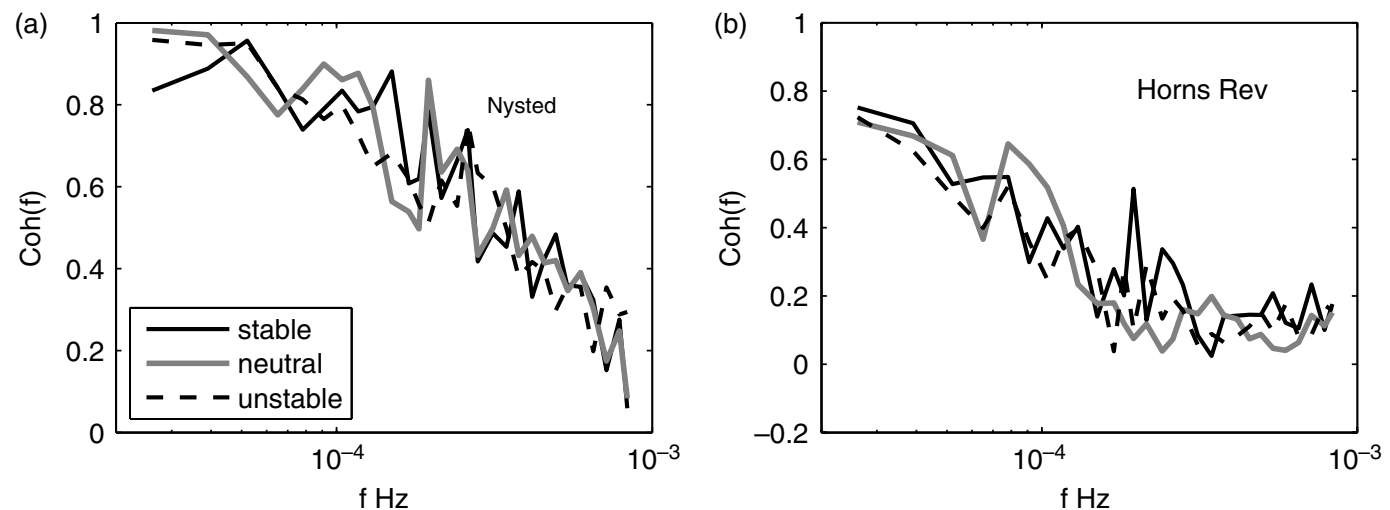

Figure 10. Coh of wind speed as functions of $f$ for lateral separation in three stability categories. (a) Between $M_{1}$ and $M_{2}$ at Nysted, stable $\left(R i_{\mathrm{B}}>0.1\right)$, neutral $\left(0 \leq R i_{\mathrm{B}} \leq 0.1\right)$ and unstable $\left(R i_{\mathrm{B}}<0\right)$. (b) Between $M_{2}$ and $M_{7}$ at Horns Rev, stable $\left(R_{\mathrm{B}}>0.015\right)$, neutral $\left(0 \leq R_{\mathrm{B}} \leq 0.015\right)$ and unstable $\left(R_{\mathrm{B}}<0\right)$.

The selected 36 stable cases at Nysted with $R i_{\mathrm{B}}>0.1$ obviously correspond to atmospheric motions with damped fluctuations at the scales $10 \mathrm{~min}$ to $3 \mathrm{~h}$ than the 42 cases from Horns Rev with comparable stability conditions.

The selected 197 unstable cases at Horns Rev with $R i_{\mathrm{B}}<0$ show significantly higher fluctuations, very likely due to the actively convective systems including cell structures that are common in this area (Vincent et al., 2010, 2012a), which are less likely to occur at Nysted even with comparable unstable conditions. In Figure 11, the mean power spectrum for 18 individual cell cases from Horns Rev $M_{2}$ clearly show higher energy amplitude of wind speed than the climatological spectrum. The 18 days are for the longitudinal separation of $M_{2}$ and $M_{7}$, identified from visual satellite images from 2003 to 2006.

Also, the local stability does not seem to have a systematic impact on the coherence for the stationary data (Figure 10).

It is still an open question how the $3 \mathrm{D}$ small-scale turbulence transitions to the mesoscale range under different stability conditions. The high-frequency tail in the 'mesoscale range' presented here likely represents an interface between mesoscale and microscale variability. From our measurements it seems that, although individual cases demonstrate fluctuations in the power spectrum in various ways, these fluctuations are averaged out when all situations are put together, as shown in the annual and seasonal spectra. It could then be questioned how the spectrum will look in a place where one particular atmospheric motion is present most of the time, e.g. cell convection is present about $50 \%$ of the time over Greenland and the Barents Sea region in wintertime (Brümmer and Pohlman, 2000). In this case, one might expect higher energy even in the climatological spectrum.

While we cannot draw decisive conclusions on the impact of stability, we may need to argue about the representativeness of the bulk Richardson numbers $R i_{\mathrm{B}}$ and $R_{\mathrm{B}}$ that are calculated from one point, even with the daily mean values, for describing properly the largescale stability conditions. In the future, we might consider using the bulk Richardson number of the whole boundary layer (which could be calculated from mesoscale models or fine-resolution global models) and consider the spatial distribution of it, hopefully to improve the description of the background stability for this purpose.

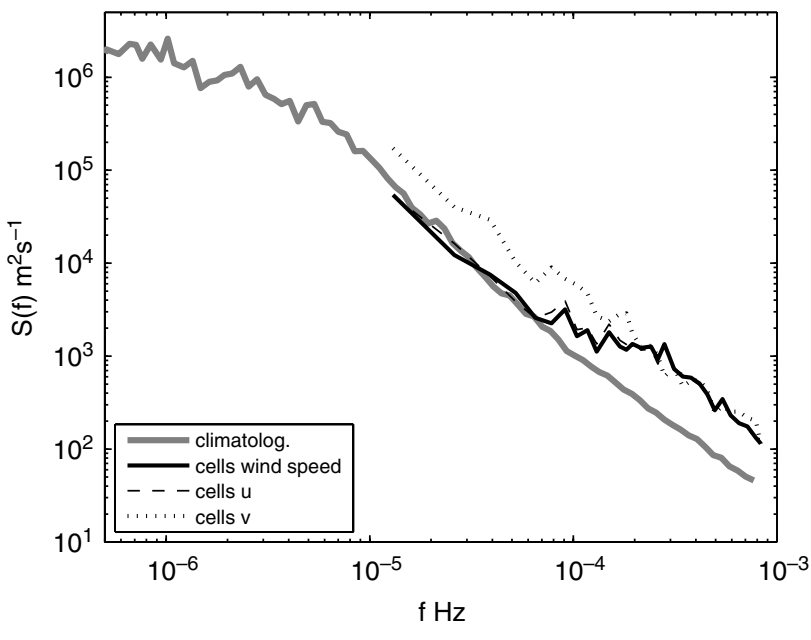

Figure 11. Mean power spectrum of 18 cases with open cell structures at Horns Rev, together with the mean annual spectrum (climatolog.) from Figure 3(c).

\subsection{On the universality of the spectra}

The spectral behaviour for meso- to macro-scales seem to be well described by the combination of $-5 / 3$ and -3 slopes using Eq. (4), in analogy to Lindborg's description for the wave number domain. There is a question whether our data from two offshore sites are representative only of offshore conditions. For this, we used measurements from five more stations across Denmark and plotted their spectra together with those from Nysted and Horns Rev in Figure 12. The locations of these sites can be found in Figure 1(a). Note that, except for Høvsøre where 2006 was used, the data from 2001 were used for all other sites because the data coverage was almost $100 \%$ for all. Note also that the measurement heights vary from 24 to $100 \mathrm{~m}$, which is expected to be partly responsible for some of the spectral energy amplitude differences. Overall, it can be concluded that the spectra from all these sites, including land, coastal and offshore, are consistent and therefore the power spectra from Nysted and Horns Rev in the meso- to macro-scales do represent a universality for midlatitudes. It should be noted here that all our measurements are from flat terrain; it still needs to be examined if the power spectra are similar in mountainous areas. However, this universality does not dispel the possibility that there is slight vertical variation of 


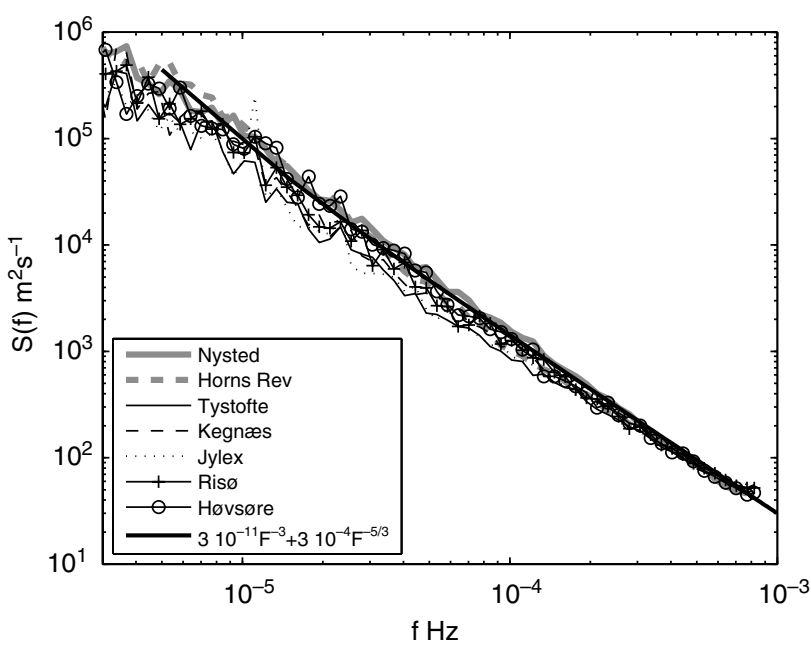

Figure 12. Annual power spectra of wind speeds from various stations.

the spectral energy amplitude, as shown in our two offshore sites (Figure $3(b, d)$ ). This vertical increase of the energy amplitude is very small and it is speculated to be sitedependent. For all year round, the atmosphere at Horns Rev is much better mixed vertically due to its dominant unstable conditions and so the height dependence here is negligible; however for most of the year the atmosphere around Nysted is stable, and here the spectrum varies slightly more with height.

Comparing with the spectra from measurements as in Gage and Nastrom (1986), we convert Eq. (1) to the radian wave number domain and obtain

$$
k E(k)=d_{1 r} k^{-2 / 3}+d_{2 r} k^{-2}
$$

where $k=k_{1} /(2 \pi)$, so that

$$
d_{1 r}=d_{1}(2 \pi)^{-2 / 3} \text { and } d_{2 r}=d_{2}(2 \pi)^{-2} .
$$

At the same time, according to the our measurements, Eq. (4) gives

$$
f S(f)=a_{1} f^{-2 / 3}+a_{2} f^{-2} .
$$

We calculated $k E(k)$ and $f S(f)$ in order to compare their the magnitude and shape for scales smaller than $1 / T$ where the slope of $E(k)$ or $S(f)$ is $-5 / 3$. However, if we want to put the two on the same figure for the comparison, a Taylor transformation is needed. It is not a simple approach to find out $\mathbf{u}_{0}$ which represents a mean speed over an area of hundreds of kilometres over a deep layer of atmosphere. The wind speed $U_{0}$ at one particular height as we used in the scaling $f d / U_{0}$ is not appropriate for this purpose. A large dataset from a global or regional model is needed; in Larsén et al. (2011), $\mathbf{u}_{0}$ was calculated as the mean speed over the boundary layer using mesoscale modelled winds. Nevertheless, if we start the comparison at where the spectral slope transition from -3 to $-5 / 3$ begins and continue for smaller scales, it is found that $d_{1 r} k^{-2 / 3}$ is very comparable to $a_{1} f^{-2 / 3}$. This supports the universality of the mesoscale power spectrum. If we let $k E(k)=f S(f)$ for this range, the Taylor transformation would suggest a magnitude of $\mathbf{u}_{0}$ about $7 \mathrm{~m} \mathrm{~s}^{-1}$. We could get a rough idea of the magnitude of $\mathbf{u}_{0}$ in this area through winds from mesoscale models, e.g. Larsén et al. (2010) shows that the mean wind speed at $10 \mathrm{~m}$ in Northern Europe is in the range of 5 to $9 \mathrm{~m} \mathrm{~s}^{-1}$, according to the regional model REMO.

From a totally different approach, van Zandt (1982) derived that the mesoscale kinetic energy spectrum also corresponds to a slope of $-5 / 3$ as a result of interactions of a broadband population of atmospheric gravity waves. For the frequency domain, in stable conditions, Fritts and van Zandt (1987) started with the general wave spectrum from Garrett and Munk (1975) as a function of horizontal wave number $k$ and radian intrinsic frequency $\omega^{\prime}$, which is between the Coriolis frequency, $f_{c}$, and the Brunt-Väisälä frequency, $N$ (Eq. (14) in Fritts and van Zandt, 1987). To derive the spectrum observed by a stationary sensor, they took into account the effect of Doppler shift. Assuming the angle between the flow and $k$ is 0 or $180^{\circ}$, and assuming the portion of energy from random waves with phase speed $c=\omega^{\prime} / k \geq 0$ equals that with $c=\omega^{\prime} / k<0$, for the observed frequency $f_{\mathrm{c}} \ll 2 \pi f<N$, it was derived that the observed power spectrum is

$$
S_{\mathrm{F}}(f) \simeq \frac{E_{0}}{f_{\mathrm{c}}\left(2 \pi f / f_{\mathrm{c}}\right)^{2}}\left(1+\frac{\beta^{2}}{1+\beta}\right),
$$

where $S_{\mathrm{F}}$ denotes the power spectrum of Fritts and van Zandt, $E_{0}$ is the total energy density for internal gravity waves, including kinetic and potential energy, and $\beta$ is the ratio of the mean wind and a characteristic intrinsic horizontal phase speed of the wave field. $\beta$ describes the Doppler shift effect and it ranges between 0 (no waves) and 10 (reported for the lower stratosphere; Smith, 1987). With the $\beta$ effect, one would expect that in reality, with random waves of different characteristics filling the stable atmosphere, the spectral energy $S(f)$ would vary within a certain range. From measurements in various research papers, Sidi et al. (1988) adopted $E_{0}=7.5 \mathrm{~J} \mathrm{~kg}^{-1}$ as a typical value for the tropospheric gravity wave total energy, again including the kinetic and potential energy.

We plot this model on top of our stable cases in Figure $6(\mathrm{a}, \mathrm{d})$, using $\beta=0$ and assuming that the kinetic energy is half the total energy $S(f)=(1 / 2) S_{\mathrm{F}}(f)$, based on the observation from Gage and Nastrom (1986) that the potential temperature spectrum is more or less the same as the kinetic spectrum. Note that, in deriving Eq. (7), the authors have deliberately chosen a spectral slope of -2 in order to obtain an analytical solution, although they commented on the possibility of a $-5 / 3$ slope. This is an interesting surprise that the universal spectrum description for random gravity waves by Fritts and van Zandt (1987) is a good approximation for the measured spectrum in stable conditions (Figure 6(a,d)).

\subsection{On 2D isotropy}

For the stationary data, the vertical variation of the power spectrum in the mesoscale range has been shown to be small, only comparable to the seasonal variation, which is also very small. In the horizontal, Figure 6 clearly shows that the along-wind and across-wind components, $u$ and $v$, have very similar spectral characteristics, with the power spectrum for $u$ slightly larger than that for $v$ for $f>10^{-4} \mathrm{~Hz}$, and $u$ and $v$ are not coherent. It has to be admitted that it is an approximate assumption of stationarity we have used here for a period of $24 \mathrm{~h}$, even with the restrictions of wind speed and direction (section 3 ). These restrictions filter out several 

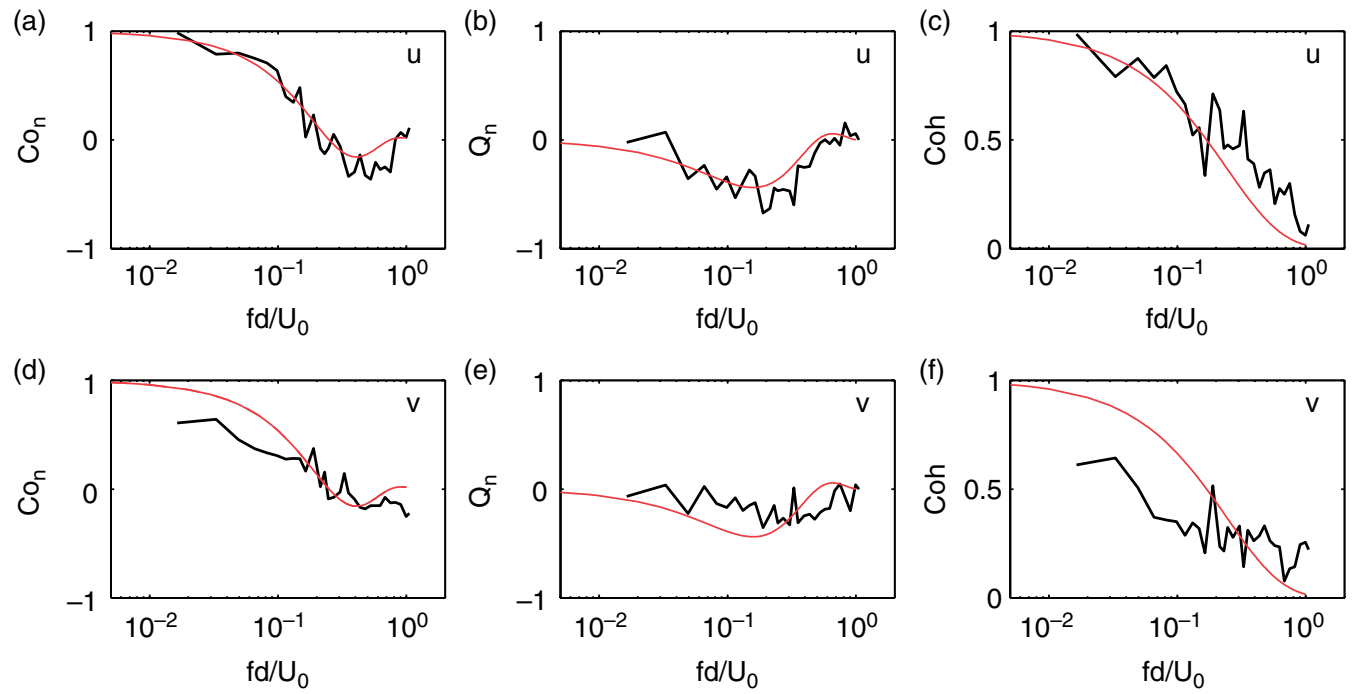

Figure 13. $C o_{n}, Q_{n}$ and $C o h$ between $M_{2}$ and $M_{7}$ at Horns Rev for the open cell cases, longitudional separation. The thin smooth curves in $(\mathrm{a}, \mathrm{d})$ and $(\mathrm{b}, \mathrm{e})$ are respectively from Eqs (18) and (19) in V2012 corresponding to zero inflow angle relative to the masts' orientation $\left(C o_{n}=\exp \left(a f d / U_{0}\right) \cos \left(b f d / U_{0}\right)\right.$ and $\left.Q_{n}=\exp \left(a f d / U_{0}\right) \sin \left(b f d / U_{0}\right)\right)$. The smooth curves in $(\mathrm{c}, \mathrm{f})$ are Eq. (5) with $\alpha=0^{\circ}$. This figure is available in colour online at wileyonlinelibrary.com/journal/qj
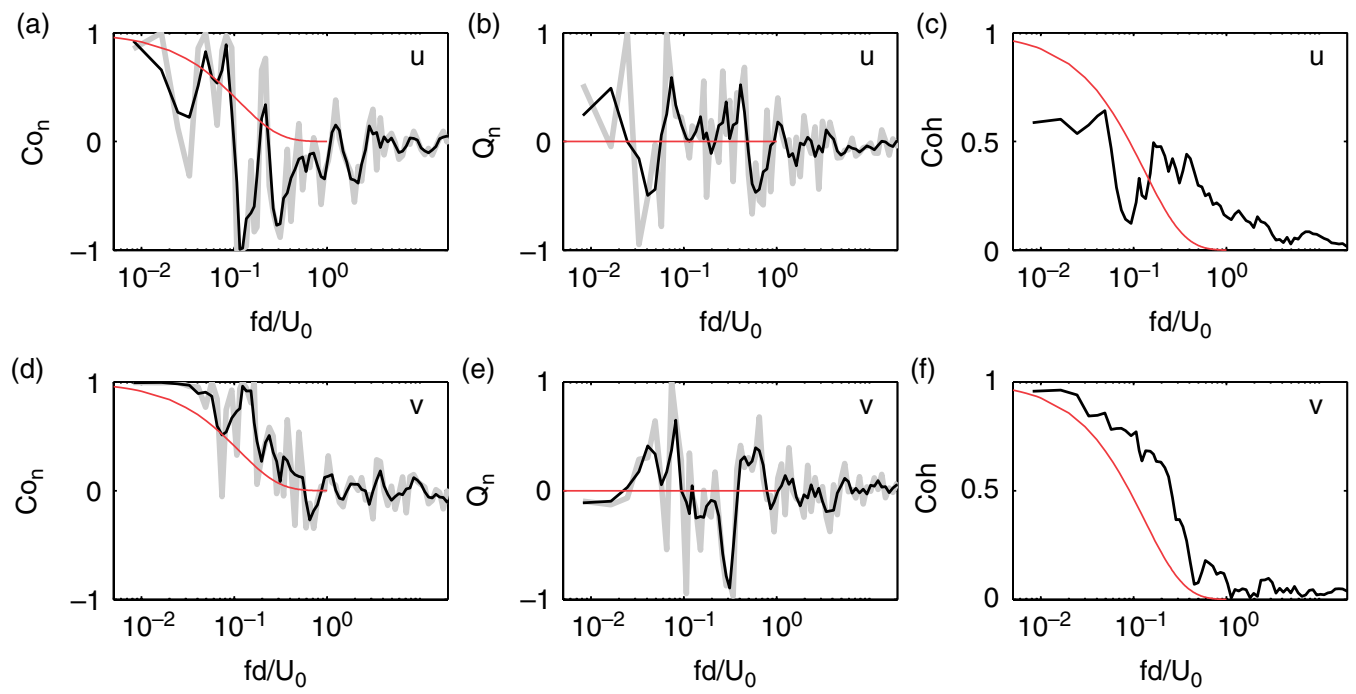

(e)
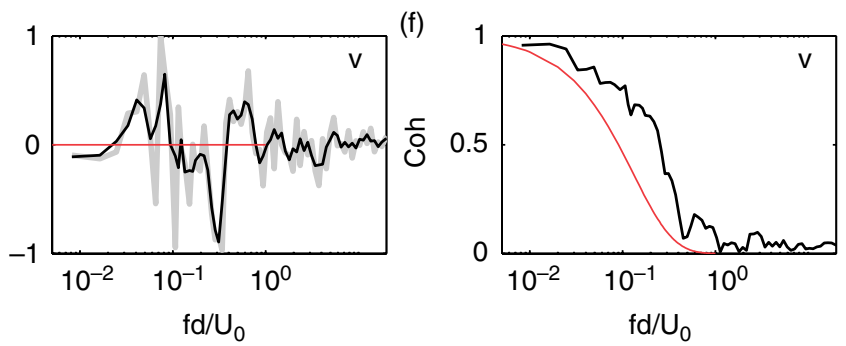

Figure 14. $C o_{n}, Q_{n}$ and Coh between $M_{1}$ and $M_{3}$ at Nysted for the gravity wave case studied in Larsén et al. (2011). The black curves are running means of three values taken from the grey curves. The thin smooth lines in (a,d) and (b,e) are respectively from Eqs (18) and (19) in V2012 (as in Figure 13) corresponding to inflow angle $\alpha=270^{\circ}$ relative to the masts' orientation. The smooth curves in (c,f) are from Eq. (5) with $\alpha=270^{\circ}$. This figure is available in colour online at wileyonlinelibrary.com/journal/qj

mesoscale phenomena that are often present in coastal areas, such as open cell conditions and sea breezes (with significant direction change). Even so, the ranges of wind speed and direction allowed here are not strict stationarity conditions. This indicates uncertainty to some degree when dividing the winds into the $u$ and $v$ components. Using shorter time series than $24 \mathrm{~h}$ will have less problems on this issue, but it will then provide a very limited frequency range. The uncertainty in the calculation of the spectrum is also higher for the lower frequencies. Therefore it cannot be certain that anisotropy applies for $f<10^{-4} \mathrm{~Hz}$. In Lindborg (1999), it was shown that, whereas it cannot be certain that the turbulence is $2 \mathrm{D}$ isotropic for the $-5 / 3$ part of the spectrum, it is certain for the larger-scale part of the spectrum where the slope is -3 . By definition, 2D isotropy means that the turbulence of the wind is the same regardless of the direction. Without measurements over the whole space, it is hard to examine. Nevertheless, mesoscale modelling through the Weather
Research and Forecasting model has provided us with such a wind distribution. Skamarock (2004) and Larsén et al. (2011) reported that the power spectra of the wind speeds from different transects in the model domain have the same power spectra. The 2D isotropy character was also observed by Frehlich and Chelton (1986) with the Seasat scatterometer in midlatitudes but not for the tropical region.

For the stationary data, $u$ and $v$ also have very similar two-point spatial coherences, even though the scatter could be considerable due partly to a limited number of samples. In V2012, cases with measurements downwind of the wind farm are included and therefore the number of cases is much greater than in this study. In spite of the possible wake effect, the coherence structure found in V2012 is consistent with that in the current study, suggesting that the limited number of cases used here are representative.

Apart from the stationary data, the power spectra, coand quadrature spectra and coherence have shown quite 
different characteristics for $u$ and $v$ for mesoscale structures such as cells and gravity waves. For these cases, the simple descriptions for the stationary data are not suitable and there are strong signals of anisotropic turbulence. One may argue that these features belong to a sub-mesoscale range where it bears 3D characteristics. For the open cell structures at Horns Rev, Figure 11 shows that the spectra for $u$ and $v$ are not the same and Figure 13 shows (for the longitudinal separation $\left.f d / U_{0}>0.25\right)$ that $C o_{n}$ and $Q_{n}$ do have more profound correlation and phase delay of $u$ when the cell size is comparable to the separation distance between $M_{2}$ and $M_{7}$. The result for wind speed is very similar to that for $u$. The distributions of the three parameters are not the same for the $u$ and $v$ components, suggesting the spatial spectral structure is not 2D isotropic for cell conditions. For the gravity wave case from Larsén et al. (2011), we used $1 \mathrm{~s}$ time series from 6 November 2006 to calculate $C_{n}, Q_{n}$ and Coh between $M_{1}$ and $M_{3}$ and the results are presented in Figure 14. Since the wind was blowing through the wind farm, we may expect some wake effects, but these effects are not immediately clear in the spectra. As given in Larsén et al. (2011), the wavelength of the gravity waves is about $12 \mathrm{~km}$, thus $M_{1}$ and $M_{3}$, with a distance of about $8 \mathrm{~km}$, are approximately $3 / 4$ wavelength apart. The spectral characteristics of $u$ and $v$ are different. The $u$ component, aligning with the wave propagation direction, fluctuates wavelike with $f d / U_{0}$; it sometimes becomes entirely negatively correlated at the two masts. On the other hand, $\mathrm{Co}_{n}$ for the $v$ component decays exponentially with $f d / U_{0}$ but has a better correlation than the average curve for the stationary data (the thin smooth curve). At the same time, the phase shift varies between $-180^{\circ}$ and $180^{\circ}$ (Figure $14(\mathrm{~b}, \mathrm{e})$ ).

\section{Conclusion}

The following summarizes the main new findings from this study. They are important for wind energy planning and power integration for modern wind farms.

- The standard point meteorological measurements from tall meteorological masts over the sea can be used for studying the spectral structures of winds in the mesoscale range. The climatological wind power spectra from two offshore sites have shown some universality characteristics in agreement with the findings in the literature: there is a $-5 / 3$ spectral slope in the mesoscale range which transitions to -3 toward synoptic and planetary scales. The slope transition is most dominant for winter months when the baroclinic instabilities are the strongest in midlatitudes. The power amplitude is consistent with various theoretical arguments and spatial measurements.

- In the mesoscale frequency range, for the stationary data, the along- and cross-wind components, $u$ and $v$, are not correlated and their spectral behaviours, including the power spectrum, the co- and quadrature spectrum and coherence, are very similar.

- The stability parameter calculated from one point measurement, the bulk Richardson number, is not sufficient in representing the specific atmospheric structures under different stability conditions. These special mesoscale features bear their own spectral characteristics. They do bring variations to the group of spectra but did not significantly change the climatological spectrum for the two sites of our study.
- The Taylor hypothesis is valid for the largest structures in the normal daily time series. The smaller structures are less correlated and become uncorrelated at higher $f d / U_{0}$. The integral time-scale of the local weather is found to be a useful scale for applying scaling of $f d / U_{0}$ and the Taylor hypothesis. This integral scale is also found to be closely related to the spectral slope transition from $-5 / 3$ to -3 .

\section{Acknowledgements}

This work is supported mainly by the Danish project 'Mesoscale variability' (PSO 2007-1-7141) and partly by the ICEWIND project and by the EU under project no. ENER/FP7EN/249812/'TWENTIES'. The second author acknowledges the support from the Danish Council for Independent Research -Technology and Production Sciences (10-093196). We thank Poul Sørensen from DTU for discussions. The authors acknowledge Dong Energy and Vattenfall for the measurements. The authors have no conflict of interest to declare.

\section{References}

Batchelor GK. 1969. Computation of the energy spectrum in homogeneous two-dimensional turbulence. High Speed Comput. Fluid Dyn. Phys. Fluid. suppl. II, 223-239.

Boer GJ, Shepherd TG. 1983. Large-scale two-dimensional turbulence in the atmosphere. J. Atmos. Sci. 40: 164-184.

Brown PS, Robinson GD. 1979. The variance spectrum of tropospheric winds over Eastern Europe. J. Atmos. Sci. 36: 270-286.

Brümmer B, Pohlmann S. 2000. Wintertime roll and cell convection over Greenland and Barents Sea region: A climatology. J. Geophys. Res. 105: 15559-15566.

Davenport AG. 1961. The spectrum of horizontal gustiness near the ground in high winds. Q. J. R. Meteorol. Soc. 87: 194-211.

Frehlich MH, Chelton DB. 1986. Wavenumber spectra of Pacific winds measured by the Seasat scatterometer. J. Phys. Oceanogr. 16: 741-757.

Fritts DC, van Zandt TE. 1987. Effects of Doppler shifting on the frequency spectra of atmospheric gravity waves. J. Geophys. Res. 92: 9723-9732.

Garrett CJR, Munk WH. 1975. Space-time scales of internal waves: A process report. J. Geophys. Res. 80: 291-297.

Gage KS, Nastrom GD. 1986. Theoretical interpretation of atmospheric wavenumber spectra of wind and temperature observed by commercial aircraft during GASP. J. Atmos. Sci. 43: 729-740.

Högström U, Smedman A-S, Bergström H. 1999. A case study of two-dimensional stratified turbulence. J. Atmos. Sci. 56: 959-976.

Kao SK, Wendell LL. 1970. The kinetic energy of the large-scale atmospheric motion in wavenumber-frequency space. I: Northern Hemisphere. J. Atmos. Sci. 40: 749-761.

Kraichnan RH. 1967. Inertial ranges in two-dimensional turbulence. Phys. Fluids 10: 1417-1423.

Kristensen L, Panofsky H, Smith S. 1983. Lateral coherence of longitudinal wind components in strong winds. Boundary-Layer Meteorol. 21: 199-205.

Kristensen L, Kirkegaard P. 1986. 'Sampling problems with spectral coherence’. Risoe-R-526(EN), Risø National Laboratory: Roskilde, Denmark. http//:www.risoe.dk

Kristensen L, Kirkegaard P, Mann J. 2002. Sampling statistics of atmospheric observations. Wind Energy 5: 301-313.

Lange B, Larsen S, Højstrup J, Barthelmie R. 2004. Importance of thermal effects and sea surface roughness for offshore wind resource assessment. J. Wind Eng. Ind. Aerodyn. 92: 959-988.

Larsen SE, Courtney M, Mahrt L. 1990. 'Low-frequency behavior of horizontal velocity spectra in stable surface layers'. In Proceedings of Ninth Symposium on Turbulence and Diffusion, Amer. Meteorol. Soc: Boston, Mass. 401-404.

Larsén XG, Mann J. 2006. The effects of disjunct sampling and averaging time on mean maximum wind. J. Wind Eng. Ind. Aerodyn. 94: $581-602$.

Larsén XG, Mann J, Berg J, Göttel H, Jacob D. 2010. Wind climate from the regional climate model REMO. Wind Energy 13: 279-296. 
Larsén XG, Larsen S, Badger M. 2011. A case study of mesoscale spectra of wind and temperature, observed and simulated. Q. J. R. Meteorol. Soc. 137: 264-274.

Larsén XG, Ott S, Badger J, Hahmann A, Mann J. 2012. Recipes for correcting the effect of mesoscale resolution on the estimation of extreme winds. J. Appl. Meteorol. Climatol. 51: 521-533.

Lilly DK. 1983. Stratified turbulence and the mesoscale variability of the atmosphere. J. Atmos. Sci. 40: 749-761.

Lilly DK, Petersen EL. 1983. Aircraft measurements of atmospheric kinetic energy spectra. Tellus 35: 379-382.

Lindborg E. 1999. Can the atmospheric kinetic energy spectrum be explained by two-dimensional turbulence? J. Fluid Mech. 388: 259-288.

Lindborg E, Tung KK, Nastrom GD, Cho JYN, Gage KS. 2010. Comment on 'Reinterpreting aircraft measurements in anisotropic scaling turbulence’ by Lovejoy, et al. (2009). Atmos. Chem. Phys. 10: 1401-1402.

Mann J. 1994. The spatial structure of neutral atmospheric surface-layer turbulence. J. Fluid Mech. 273: 141-168.

Nanahara T, Asari M, Sato T, Yamaguchi K, Shibata M, Maejima T. 2004. Smoothing effects of distributed wind turbines. Part 1 . Coherence and smoothing effects at a wind farm. Wind Energy 7: 61-74.

Nastrom GD, Gage KS. 1985. A climatology of atmospheric wavenumber spectra of wind and temperature observed by commercial aircraft. J. Atmos. Sci 42: 950-960.

Pedersen TF. 2004. 'Characterisation and classification of Risø P2546 cup anemometer'. Risoe-R-1364 (ed. EN) Risø National Laboratory: Roskilde, Denmark. http://www.risoe.dk/rispubl/VEA/veapdf/ris-r1364.pdf

Pedersen TF, Gjerding S, Ingham P, Enevoldsen P, Hansen JK, Jørgensen HK. 2003. 'Wind turbine power performance verification in complex terrain and wind farms'. Risoe-R1330 (ed. EN) Risø National Laboratory: Roskilde, Denmark. http://www.risoe.dk/rispubl/VEA/veapdf/ris-r-1330.pdf

Peña A, Gryning S, Hasager CB. 2008. Measurements and modeling of the wind speed profile in the marine atmospheric boundary layer. Boundary-Layer Meteorol. 129: 479-495.

Pope SB. 2000. Turbulent Flows. Cambridge University Press: Cambridge, UK.
Schlez W, Infield D. 1998. Horizontal two-point coherence for separations greater than the measurement height. Boundary-Layer Meteorol. 87: 459-480.

Shivamoggi BK. 2000. Direct and inverse cascades in two-dimensional turbulence with a generalized enstrophy invariant. Internat. J. Theor. Phys. 39: 83-87.

Sidi C, Lefrere J, Dalaudier F, Barat J. 1988. An improved atmospheric buoyancy wave spectrum model. J. Geophys. Res. 93: 774-790.

Skamarock WC. 2004. Evaluating mesoscale NWP models using kinetic energy spectra. Mon. Weather Rev. 132: 3019-3032.

Smedman A-S. 1987. Some additional coherence data in the inertial subrange. J. Climate Appl. Meteorol. 26: 1770-1773.

Smith SA. 1987. Evidence for a saturated spectrum of atmospheric gravity waves. J. Atmos. Sci. 44: 1404-1410.

Sørensen P, Hansen AD, André P, Rosas C. 2002. Wind models for simulation of power fluctuations from wind farms. J. Wind Eng. Ind. Aerodyn. 90: 1381-1402.

Tung KK, Orlando WW. 2002. The $k^{-3}$ and $k^{-5 / 3}$ energy spectrum of atmospheric turbulence: quasi-geostrophic two-level model simulation. J. Atmos. Sci. 60: 824-835.

van Zandt TE. 1982. A universal spectrum of buoyancy waves in the atmosphere. Geophys. Res. Lett. 9: 575-578.

Vincent CL, Pinson P, Giebel G. 2010. Wind fluctuations over the North Sea. Int. J. Climatol. DOI: 10.1002/joc.2175

Vincent CL, Larsén XG, Larsen SE, Sørensen P. 2012. Cross-spectra over the sea from observations and mesoscale modelling. Boundary-Layer Meteorol. (in press).

Vincent CL, Hahmann AN, Kelly MC. 2012a. Idealized WRF simulations of open cellular convection over the sea. Boundary-Layer Meteorol. 142: $103-121$

Wikle CK, Milliff RF, Large WG. 1999. Surface wind variability on spatial scales from 1 to $1000 \mathrm{~km}$ observed during TOGA COARE. J. Atmos. Sci. 56: 2222-2231.

Woods JW, Davy RJ, Russell CJ, Coppin PA. 2011. Cross-spectrum of wind speed for meso-gamma scales in the upper surface layer over southeastern Australia. Boundary-Layer Meteorol. 141: 93-116. 